\title{
Structural performance of hybrid sandwich slabs under shear loading
}

\begin{abstract}
In a hybrid panel with glass fiber reinforced polymer (GFRP) bottom skin and ribs, and deflection hardening cementitious composites (DHCC) top layer, it is very important to provide good shear connection between these various components in order to increase the load carrying capacity of the resulting hybrid slabs and a larger increment of deflection before the occurrence of the structural softening of this panel. The effectiveness of the proposed hybrid sandwich panels strongly depends on the performance of the shear connectors. The efficiency of indented shear connectors in improving the flexural performance of hybrid sandwich panels is here demonstrated. Since the efficiency of indented shear connectors in the hybrid sandwich panels is unknown, efforts are made in this paper in investigating the shear performance of hybrid slabs. A special focus is given on the indented shear connector's behavior, considering different shear span ratios in ranges of $2.00,1.39$, and 0.77 . In this regard, six hybrid sandwich panels were manufactured and experimentally tested under different shear loads. Then, the results are interpreted comprehensively.

The results obtained show that the GFRP rib thickness and height, and shear span ratios influence the damage events and the structural performance of the hybrid sandwich panels. Moreover, it was observed that using indented shear connectors in the hybrid slabs, regardless of the shear span ratios, provides high load capacity, high stiffness, and large residual deflection.
\end{abstract}

Keywords: Hybrid sandwich panels, Deflection Hardening Cement Composites (DHCC), Glass fiber reinforced polymer (GFRP), Indented shear connectors, Shear loading. 


\section{Introduction}

During the last decade, application of sandwich panels has increased in civil engineering applications, due to high strength to weight ratio, easy installation, and good acoustic and insulation properties [1]. Sandwich panels are commonly composed of two top and bottom skins, separated by foam core layer. The foam cores transfer the shear stresses between the top and bottom skins. Low load carrying capacity is detected as the main weakness of this type of sandwich panel [2]. Regarding this fact, various studies have been executed on improvement of the structural performance of sandwich panels.

In 2007, Keller et al. proposed a new lightweight hybrid bridge deck. This structural system was consisted of three layers, including a fiber-reinforced polymer (FRP) sheet as the bottom layer, T-upstands as the tensile skin, a lightweight concrete as the core for transferring shear stresses from the top layer to the bottom layer, and a thin layer of ultrahigh performance reinforced concrete as compression skin. Eight beams were experimentally assessed. Differences of the beams resulted from differences in the lightweight concrete types and interfaces at FRP/lightweight concrete. Two mechanisms were used to introduce interface at FRP/lightweight concrete, including mechanical interlocking between lightweight concrete and shear connectors (T-upstands) and epoxy adhesive materials. The results showed that using epoxy adhesive materials averagely increased the ultimate load of the beams about $100 \%$, and the failure modes of beams were altered from ductile into brittle. Utilizing lightweight concrete with higher density (44\%) increased the ultimate load about $80 \%$. The experimental results approved feasibility of the suggested hybrid bridge deck [3].

In 2010, Fam et al. investigated flexural performance of sandwich panels, which were comprised of polyurethane foam core and glass fiber-reinforced polymer (GFRP) skins with different configurations of ribs. The results in their study revealed that integrating the ribs increases strength and stiffness of the panels, which are strongly influenced by rib configurations. In the sandwich panels without ribs, the contribution of foam core in the shear deformation was over $50 \%$. While, adding the ribs limited the shear deformation up to $20 \%$ of the total deflection [4]. He et al. presented a lightweight and cost-effective hybrid deck [5]. This system was comprised of corrugated pultruded GFRP plates with T-upstands for the tension part and reinforced concrete with steel rods as the compression part. The results showed that using concrete for encasing corrugated pultruded GFRP plates increased the 
stiffness of the hybrid sandwich panels and supported the GFRP plates with T-upstands against local buckling [5].

Norton [7] proposed a deck, comprising two skins of E-glass fabric and GFRP truss webs, in which Balsa cores filled the GFRP truss webs. A concrete layer was also used on the top skin to obtain a hybrid sandwich panel. Steel and composite connectors were employed to connect the concrete layer to top GFRP skin. The testing results showed that the bond between the concrete and top GFRP skin was inadequate and concrete layer was debonded [7].

Thanoon et al. developed a hybrid slab based on an interlocking mechanism for transferring shear stresses [8]. The proposed composite floor slab comprised a pre-cast inverted ferrocement layer, which was interconnected with the cast in situ brick-mortar layer. This system transfers the horizontal shear stress between the interfaces of the layers. In this study, eleven slabs were assessed under pure shear loading. The results showed that the proposed interlocking mechanism proposed is an efficient and low-cost solution for transferring shear stresses [8].

Alizadeh et al. proposed a cost-effective composite bridge deck comprising multiple steel box cells, a concrete slab, and a GFRP layer [9]. The behavior of this deck was experimentally and numerically assessed. In this system the concrete top layer was connected to the steel perforated shear connectors, and shear stresses were transferred to the bottom GFRP skin. The structural performance of this system was evaluated under three-point bending tests [9]. The results revealed that using perforated rib shear connectors provided composite action between concrete slab and steel boxes [9]. The main damages resulted from yielding of the steel boxes and crushing of the top concrete layer.

Based on the abovementioned studies, that were mainly dedicated to the development and analysis of hybrid sandwich panel solutions, one main problem was detected concerning the transfer of shear stresses from the top to the bottom skins [6-7]. Therefore, the present study was conducted to evaluate and overcome this issue in hybrid sandwich panels.

In 2015, Mastali et al. proposed a new hybrid DHCC-GFRP sandwich panel which was comprised of four components, including a deflection hardening cementitious composites (DHCC) layer as the top compression skin, a GFRP skin as the bottom tension skin, and GFRP ribs and foam core as shear transferring elements from the top layer to the bottom layer [10]. Hybrid sandwich slabs were experimentally assessed under flexural loading. The results indicated that these hybrid slabs have high ultimate load, high stiffness, high ductility and large residual load carrying capacity. The slabs presented an almost linear behavior up to the ultimate load, followed by a gradually load carrying degradation in the structural softening. The observed nonlinearities were mainly caused by the damage at the GFRP 
ribs/DHCC connection. High stress concentration was formed around the perforated shear connectors [10]. Therefore, indented shear connectors were proposed in Ref [11] to postpone damage occurring in GFRP ribs and also, to provide a higher load carrying capacity with increasing the sectional area of DHCC dowels. Hybrid slabs were assessed experimentally under a four-point bending test. The results indicated that the stiffness of the connection at GFRP ribs/DHCC layer significantly affects the ultimate load and residual load capacity of hybrid slabs.

According to the literature, there is no study reporting the shear performance of hybrid sandwich panels. Most studies were assigned to investigate the structural performance of sandwich panels under flexural loading. Therefore, in the present study, the main aim is to investigate the structural performance of hybrid slabs under shear loadings with special focus on the behavior of the shear connection provided by indented connectors materialized in the GFRP ribs. In this context, six hybrid slabs with different lengths are investigated.

\section{Geometry and structural concept of the hybrid sandwich slab}

The proposed hybrid sandwich panel is comprised of four components, including DHCC material as top layer, GFRP skin as bottom layer, GFRP rib to transfer shear stresses from DHCC layer to GFRP skin, and polyurethane foam core, as shown in Figs 1a and 1b.

Fig 1. Schematic figure of the hybrid sandwich panels

The dimensions of slab's components are indicated in Fig. 2. Meaning of the letters, which presented in Fig. 2, listed in a column of Table 1.

Fig 2. Geometry characterization of the proposed hybrid sandwich panels

Table 1. Geometrical properties of the proposed slabs in details

In the hybrid slabs, DHCC layer connects to GFRP ribs through indented shear connectors. To create indented shear connectors in GFRP ribs, as shown in Fig. 1b, a simple technique was adopted by drilling small diameter holes. The properties of indented shear connectors are shown in Fig. 1c, which used at rib/DHCC connection. 


\section{Experimental plan}

\subsection{Materials}

Deflection Hardening Cement Composite (DHCC) is a fiber-reinforced mortar, which was used as top layer in the hybrid slab. Using this fiber reinforced cementitious layer as the compressive layer could increases the flexural stiffness and resistance against impact load, its acoustic and thermal performance, and providing extra fire protection for the core of the panel.

Cementitious mortar reinforced with $1 \%$ of volume discrete short and $3 \%$ of volume discrete long PAN fibers. The short PAN fibers had $6 \mathrm{~mm}$ length with bean-shape geometry, while the long PAN fibers had $12 \mathrm{~mm}$ length with trihedral circles geometry. The average flexural strength obtained $7.85 \mathrm{MPa}$, at $3.47 \mathrm{~mm}$ of deflection under four point bending test. More details on mixture ingredients, mixing process and test setup of the DHCC material can be found in [10-11]. The average compressive strength and Young's modulus of DHCC material, measured from uniaxial compression tests on cubes of $50 \mathrm{~mm}$ edge with age of 28 days, were equal to $24 \mathrm{MPa}$ and $11 \mathrm{GPa}$, respectively. GFRP sheets with different mechanical properties used the skins and the ribs of Slab 1 and Slab 2. The skins used the longitudinal and transversal fibres, which oriented at 0 and 90 degree, respectively. Since in the ribs, fibers oriented at three directions, including 0,90 , and \pm 45 degree which the highest fibre reinforcement and predominant axial stress fields were orientated at \pm 45 degrees. All details about lay-up of fiber layers used for GFRP sheets can be achieved from [10]. The average values of the main properties of GFRP sheets, including tensile strength, ultimate strain, and elasticity modulus were obtained by executing uniaxial tensile tests according to recommendations of [12], as listed in Table 2.

\section{Table 2. The obtained mechanical properties for ribs and skins}

In hybrid slabs, shear stresses are mainly transferred from top DHCC layer to GFRP skin layer by GFRP ribs, while the contribution of the foam core on the load carrying capacity of the panel was ignored due to premature failures can be occurred in the foam cores.

In the proposed hybrid slab, the foam cores provide support for DHCC layer and increase the resistance against buckling in the GFRP ribs. Regarding the compressive stress expected to occur in the foam core, compressive behavior of Polyurethane foam cores with density of $42.5 \mathrm{~kg} / \mathrm{m}^{3}$ under uniaxial compressive loads obtained based on recommendations of [13], where foam cores adopted the square cross section of $70 \times 70 \mathrm{~mm}^{2}$ and a length of $50 \mathrm{~mm}$. According to the experimental results obtained, this material presents a very high plastic compressive deformation under compression loading, with a 
pseudo yield compressive stress of $0.18 \mathrm{MPa}$ after an almost initial linear branch of elasticity modulus of $5.83 \mathrm{MPa}$.

\subsection{Manufacturing process}

GFRP ribs and skin with pre-installed foam cores were fabricated by using vacuum assisted resin transfer molding (VARTM) process [14]. Fabrication processes of the hybrid sandwich panels are included: 1) Preparation of mold and fiber layers lay-up for GFRP skins and ribs. The mold that was used for fabrication of the composite panel was a metal plate (see Fig. 3a); 2) Sealing the mold and creating a vacuum (see Fig. 3b). In this step, the air was removed from the porous material prior to admitting the resin. The air requires to be evacuated from the porous material to allow the resin to take its place; 3) Degassing of the resin; 4) Resin impregnation (see Fig. 3c). The prepared resin was injected into the mold at a very slow rate. The flow of resin was controlled by means of a peristaltic pump. It was first allowed to flow in the distribution medium for some distance and the inlet was shut off afterwards, giving the resin time to flow through the thickness. 5) De-molding the prototypes. In order to de-mold the specimens, at least 24 hours is required for curing the resin. 6) Trimming executed to separate extra parts as well as creating holes in the GFRP ribs for creating of shear connectors, as shown in Fig. 3d and Fig. 3e. Slabs were cast with using DHCC material as the top layer, and afterwards specimens were cured for 28 days (see Fig. 3f).

Fig 3. Manufacture process of hybrid slabs: a) fiber layers lay-up; b) sealing the mold; c) resin impregnation; d) trimming; e) creating of shear connectors; f) casting of DHCC layer

\subsection{Hybrid slabs}

The experimental program executed in this paper was comprised of six hybrid slabs. One slab with cross section of Slab 1 and the other one with cross section of Slab 2, considering span length of $500 \mathrm{~mm}$, were used to be assessed under shear load with span ratio of 1.39 $(=(A / H)$, where letter of $A$ in Fig. 4 depicts the arm of load and $H$ is the slab's height $)$ for Slab 1 and span ratio of 1.78 for Slab 2, where herein designated by ST1 and ST2, respectively. Moreover, two slabs with cross sections of Slab 1 and Slab 2 with span length of $900 \mathrm{~mm}$ were evaluated under shear loading with span ratio of 2 , where the specimens were designated by SS1 and SS2, respectively. Finally, two slabs with cross sections of Slab 1 and Slab 2 with span length of $500 \mathrm{~mm}$ were assessed under shear loading with span ratio of 0.77 , where the specimens were designated by SL1 and SL2, respectively. 
Fig 4. Equipped hybrid slabs for measuring of deflections, slips between GFRP ribs and DHCC layer, and uplifts (vertical deflections) of DHCC layer at support line

\subsection{Test setup and instrumentations}

Seven linear variable differential transformer (LVDT) allocated to measure displacements in different positions of slabs, as shown in Fig. 4, respectively. LVDT 3, LVDT 4, and LVDT 5 employed to measure mid-span deflections of slabs. LVDT 2 and LVDT 6 used for recording the vertical displacements of slabs on DHCC layer at both side supports. Additionally, LVDT 1 and LVDT 7 used for registering the slip between DHCC layer and GFRP ribs at both end sides.

Depending on the loading regimen, one or two steel rigid rollers were used to apply load line across the width of the specimens. Totally, four strain gauges were used for measuring strains across the panel's thickness at mid-span, including one strain gauge for measuring tensile strains at GFRP skin, two strain gauges for recording strains at GFRP ribs, and one for registering compressive strains at top surface of DHCC layer, as shown in Fig. 5. The GFRP ribs and skins were instrumented with strain gauges, type BFLA-5-5, from TML, with a $5 \mathrm{~mm}$ measuring length. One strain gauge was installed on top of DHCC layer, Type PFL30-11-3LT, from TML with $30 \mathrm{~mm}$ measuring length. All the tests were carried out based on displacement control by applying a displacement rate of $30 \mu \mathrm{m} / \mathrm{sec}$ to the slab at mid-span.

Fig 5. Positions of strain gauges in different positions of hybrid sandwich panel (Dimensions in mm)

\section{Observed damages}

Damages occurred in the hybrid slabs in several sequences. Note that no sudden failure was observed in damage sequences of the slabs during testing. The following damage sequences were recorded in the specimens SF1, SF2, SS1, SS2, ST1, ST2, and SL2 as:

1) loss of connection between the foam cores and the DHCC layer (see Fig. 6a);

2) Damage in the GFRP ribs due to compressive stress (see Fig. 6b);

3) Loss bond between the GFRP rib and the DHCC layer (see Fig. 6c);

4) Splitting cracks formed on the surface of DHCC layer (see Fig. 6d);

5) Some shear cracks were formed in the foam cores (see Fig. 6e).

Since, specimen SL1 showed different damage sequences due to delamination buckling phenomenon in the GFRP rib, including:

1) loss of connection between the foam cores and the DHCC layer (see Fig. 7a); 
2) Ply delamination of GFRP rib layers (see Fig. 7b);

3) Local buckling in the GFRP ribs (see Fig. 7c);

4) Splitting cracks formed on the surface of DHCC layer (see Fig. 7d);

5) Ply delamination of GFRP rib layers in the connection zone with GFRP skin (see Fig. 7e);

6) Formation of shear cracks in the foam cores (see Fig. 7f).

Fig 6. Sequences of observed failure modes in specimens SS1, SS2, ST1, ST2, and SL2

Fig 7. Sequences of damages observed in specimen SL1

\section{Results and discussion}

In this section of the paper, comprehensive interpretations are presented on force versus deflection response, slip measured between GFRP rib and DHCC layer, force versus strain response, and composite action of the hybrid slabs applied in different load levels.

\subsection{Shear loading with span ratio of 2}

Fig. 8 shows the relation between the applied load and the deflection measured at the slabs' mid-span through various applied loadings. Figs. $8 \mathrm{a}$ and $8 \mathrm{~b}$ indicate the response of the slabs under shear loading. The specimen SS1 presented an almost linear force-deflection response up to $120.7 \mathrm{kN}$, when a deflection of $1.6 \mathrm{~mm}$ was registered (Point $\mathrm{B}$ in Fig. 8a). Despite the first register of damage was detected for a load level of about $80 \mathrm{kN}$ (Point $A$ in Fig. 8a), due to the loss of contact between foam and DHCC (Fig. 6a), the decrease of stiffness up to point $B$ was almost imperceptible. At point $B$, the damage level significantly progressed, mainly due to excessive compressive strain in the GFRP ribs (Fig. 6b) and the shear connection between these ribs. Also, the DHCC layer assured an increase of load with a larger increment of deflection, a load of $149.36 \mathrm{kN}$ and a deflection of $9 \mathrm{~mm}(=\mathrm{L} / 100$, where $L$ is equal to span length) registered at Point $C$ with a hardening behavior. By further increasing of the deflection, the deterioration of the connection between the ribs and the DHCC layer was intensified, and a splitting crack started to be visible on the top surface of the DHCC layer in alignment with the GFRP ribs (Fig. 6d). According to the obtained experimental results, an almost constant residual load carrying capacity of about $50 \mathrm{kN}$ was registered at deflection of $28.15 \mathrm{~mm}(\approx \mathrm{L} / 32)$, which was about $33 \%$ of the load corresponding to Point C. Here, shear cracks also appeared in the foam cores due to large residual deflection (Fig. 6e). 
Fig 8. Measured force versus deflection responses for specimens of: a) SS1; b) SS2; c) ST1; d) ST2; e) SL1; f) SL2

Fig. 9 shows the measured slip between the DHCC layer and GFRP ribs registered during the execution of the test. It is observed that a nonlinear increment of slip occurred at a force/deflection, corresponding to the end of the linear response of the specimen SS1 at force of $125.67 \mathrm{kN}$ and slip of $0.004 \mathrm{~mm}$, as shown in Fig. 9a. For the above slip of 3.64 $\mathrm{mm}$, where the load is equal to $143.21 \mathrm{kN}$, an abrupt reduction of load was observed. Fig. 10 presents the relationship between the slip and deflection of the specimens. As shown in Fig. $10 \mathrm{a}$, an abrupt increment of deflection occurred in Point $A$ with a deflection of $1.6 \mathrm{~mm}$. Here, by increasing the deflection increment, a linear correlation could be found up to 3.64 $\mathrm{mm}$ between the slip and deflection (the branch of AB in Fig. 10a), where the specimen SS1 experienced hardening stage. This indicates that the stiffness and load carrying capacity of the specimen SS1 are mainly governed by the GFRP ribs/DHCC layer connection.

Fig 9. Measured force versus slip responses for specimens of: a) SS1; b) SS2; c) ST1; d) ST2; e) SL1; f) SL2

Fig 10. Relationship between deflection versus slip for specimens loaded under shear with span rations of: a) 2; b) 1.39 for Slab 1 and 1.78 for Slab 2; c) 0.77

Fig. 11 indicates the variation of strains during the loading process of the specimens under different load conditions. According to the results shown in Fig. 11a, a maximum compressive strain of 0.0011 was recorded on the top of the DHCC layer (SG4), while a maximum tensile strain of 0.0018 was registered in the GFRP skin (SG1). The tensile strains measured in the GFRP ribs and skin of the specimen SS1 were much lower than the ultimate strains recorded in the direct tensile tests carried out with the specimens extracted from these components of the slab (see Table 2). During the deflection hardening stage of the specimen SS1, the compressive strains in the GFRP ribs increased significantly due to the deterioration of the shear connection between the ribs and DHCC layer.

Fig 11. Recorded strain values in different positions for specimens of: a) SS1; b) SS2; c) ST1; d) ST2; e) SL1; f) SL2

The efficiency of shear connectors under different load conditions was measured by the strain distribution across the panel's thickness at mid-span. Fig. 12 illustrates the strains in cross section at mid-span of the slab along the slab's height. The represented diagrams 
correspond to the relative load levels $0.2 \mathrm{P}_{\max }, 0.4 \mathrm{P}_{\max }, 0.6 \mathrm{P}_{\max }, 0,8 \mathrm{P}_{\max }$, and $\mathrm{P}_{\max }$. Composite action results from the capacity of the hybrid sandwich panel components of working together. This composite action will depend on the characteristics and behaviour of the shear connection provided. Thus, the composite action can be divided into three different groups in each hybrid structure, including full composite action, partial composite action, and non-composite action. The fully composite action is reflected in strains remaining essentially linear across the slab thickness. Otherwise, semi-composite action or none-composite action is achieved. The pattern of the distribution of strains across the panel's thickness was analyzed to estimate the composite action achieved by different layers in the slab. Based on the presented classification, the specimen SS1 acted in fully composite action up to load level of $0.8 P_{\max }$, while for $P_{\max }$, the specimen acted in partially composite action (see Fig. 12a). The number of shear connectors may not be enough to make the panel fully composite; therefore, increasing number of shear connectors is more likely to result in fully composite action. Considering the results obtained in [15], various parameters such as number, position, and shape of shear connectors in the GFRP ribs, height, thickness and spacing of GFRP ribs, of GFRP ribs have influence on the effectiveness on ensuring fullycomposite action in hybrid slabs. Therefore, concerning the complexity of the parameters involved in the composite action of hybrid slabs, an increased number of shear connectors should contribute to obtain a full composite action in the hybrid slabs, but this subject needs further and specific investigation.

Fig 12. Strain distribution across the panel's thickness at mid-span of: a) SS1; b) SS2; c) ST1; d) ST2; e) SL1; f) SL2

The specimen SS2 was tested based on shear load conditions with span ratio of 2. All the details about measurement devices and test setup are well described in Section 3.4. The load versus deflection response was registered for the specimen SS2, as depicted in Fig. 8b, where the specimen SS2 presented a linear-elastic behavior up to a load of $92.51 \mathrm{kN}$ and deflection of $1.96 \mathrm{~mm}$ (Point B in Fig. 8b), at which compressive damage occurred in the GFRP ribs (Fig. 6b). Loss of contact between the DHCC layer and foam was also observed in the specimen SS2, where load was recorded equal to $60 \mathrm{kN}$ (Point $A$ in Fig. 8b), which, however, did not significantly impact the slab in terms of loss of stiffness . A hardening stage was observed above a deflection of $2.32 \mathrm{~mm}$, where nonlinear damage began to propagate in the specimen SS2 due to the damage observed in the GFRP ribs, and a load of $106.58 \mathrm{kN}$ for a deflection of $7.48 \mathrm{~mm}(\approx \mathrm{L} / 120)$ was recorded in Point $\mathrm{C}$ (see Fig. 8b). Above the deflection of $7.48 \mathrm{~mm}$, the specimen SS2 entered a softening structural stage with smooth 
reduction of the load carrying capacity, Thus, this slab presented a load carrying capacity of $47.9 \mathrm{kN}$ at the deflection of $29.98 \mathrm{~mm}(\approx \mathrm{L} / 30)$, which was about $45 \%$ of the peak load. The relationship between the load versus slip between the DHCC layer and GFRP ribs for the specimen SS2 is shown in Fig. 9b, where a nonlinear increment of the slip occurred at a force/deflection corresponding to the end of the linear response of the specimen SS2 at force of $81.79 \mathrm{kN}$ and slip of $0.011 \mathrm{~mm}$. As shown in Fig. 10a, an abrupt increment of deflection occurred in Point $A$ with a deflection of $1.96 \mathrm{~mm}$, where a splitting crack started to be visible on the top surface of the DHCC layer in alignment with the GFRP ribs due to propagation of nonlinear damage in the hybrid slabs (Fig. 6d). By increasing the deflection increment, a linear correlation between the slip and deflection could be found up to a slip of $3.50 \mathrm{~mm}$ (the branch of AC in Fig. 10a), where the specimen SS2 experienced high residual load carrying capacity about $48 \mathrm{kN}$ (Fig. 6c). According to the results presented in Fig. 11b, a maximum compressive strain of 0.0016 was recorded in the GFRP ribs (SG3), and a maximum tensile strain of 0.00066 was measured in the GFRP skin (SG1). The maximum compressive strain registered on the top surface of the DHCC layer (SG 4) was equal to 0.00014 , which is low strain value when compared to ultimate compressive strain of the DHCC material (equal to 0.0024). Additionally, the strains recorded for the GFRP ribs and skin of the specimen SS2 were much lower than the ultimate strains recorded in the direct tensile tests executed in the specimens extracted from these GFRP elements (see Table 2). The specimen SS2 acted in partially composite action up to load level of $0.8 P_{\max }$, while for $P_{\max }$, the specimen acted in non-composite action (Fig. 12b).

Despite the low tensile strains measured in the GFRP skins under short-term loading conditions (both in the presented shear tests and in the flexural tests previously performed $[10,11,15])$, the authors recommend that no reduction on the GFRP skin thickness is implemented in further investigations on hybrid sandwich panels, because, as the authors reported in [15], the deflections of hybrid slabs under long-term shear and flexural loadings significantly increased when the thickness of the GFRP skins was decreased.

\subsection{Shear loading with span ratio of 1.39 for Slab 1 and 1.78 for Slab 2}

A concentrated load was applied to mid-span of Slab 1 and Slab 2 to assess shear performance of hybrid slabs, so that this type of loading provides a shear span ratio of 1.39 for Slab 1 and 1.78 for Slab 2. Two slaps, i.e., Slab 1 and Slab 2, with $500 \mathrm{~mm}$ span length, where designated ST1 and ST2 monotonically loaded and following outstand results obtained. 
The relationship between force and deflection recorded for the specimen ST1 is shown in Fig. 8c. This slab indicated a linear-elastic behavior up to a load of $140 \mathrm{kN}$ and deflection of $0.25 \mathrm{~mm}$ (Point B in Fig. 8c), where compressive damage occurred in the GFRP ribs (Fig. 6b). Like the specimens SS1 and SS2, the first damage occurred due to loss of contact between the foam and DHCC layer (Fig. 6a), in which the load level was equal to $90 \mathrm{kN}$ (Point A in Fig. 8c). However, this damage had no significant impact on the slab in terms of loss of stiffness. A plateau stage was measured above deflection of $0.25 \mathrm{~mm}$ (branch of CD in Fig. 8c), and an almost constant peak load of $146.6 \mathrm{kN}$ for a deflection of $1.8 \mathrm{~mm}$ was recorded in Point D (Fig. 8c). Above this deflection, the specimen ST1 entered a structural softening stage, where a residual load carrying capacity of $70 \mathrm{kN}$ was measured at deflection of $8.64 \mathrm{~mm}(\approx \mathrm{L} / 58)$, which was $47.75 \%$ of the peak load.

Fig. 9c depicts the measured slip between the DHCC layer and the GFRP ribs registered in the specimen ST1 during the execution of the shear test. According to the obtained results, an abrupt slip occurred at load level of $100 \mathrm{kN}$ and slip of $0.0071 \mathrm{~mm}$, where nonlinear damage began to propagate at the connection of GFRP rib/DHCC layer. As shown in Fig. 10 , most of the tested slabs in the linear-elastic stage registered large mid- span deflections corresponding to low slip values, while this was not validated for the specimen ST1. Due to propagation of nonlinear damage at the connection of GFRP rib/DHCC layer before excessive compressive strain in the GFRP ribs at deflection of $0.25 \mathrm{~mm}$, as shown in Point $A$ in Fig. 10b, large slip values were recorded. Above this deflection $(0.25 \mathrm{~mm}$, in Point A), due to concentration of damage in the connection zone and deterioration of the shear connection between the ribs and the DHCC layer, an abrupt increment of slip was measured (a slip of about $5 \mathrm{~mm}$ ). According to the results indicated in Fig. 11c, a maximum compressive strain of 0.00067 was recorded in the GFRP ribs (SG3), and a maximum tensile strain of 0.00062 was measured in the GFRP skin (SG1). Due to the deterioration of the shear connection between the ribs and DHCC layer, the compressive strain in the GFRP ribs (SG3) increased significantly. The strains registered for the GFRP ribs and skin of the specimen ST1 were much lower than the ultimate strains recorded in the direct tensile tests executed in the specimens extracted from these GFRP elements (see Table 2). Moreover, based on Fig. 12c, the specimen ST1 acted in fully composite action up to load level of $0.8 P_{\max }(117.28$ $k N)$, while for $P_{\max }$, the specimen acted in non-composite action.

Fig. 8d represents the force versus deflection response of the specimen Slab 2 under shear loading with span ratio of 1.78 . Like other tested slabs, in the specimen ST2, the first damage occurred due to loss of contact between the foam and DHCC layer (Fig. 6a), in which the load level was equal to $50 \mathrm{kN}$ (Point A in Fig. 8d) and its impact in term of stiffness was almost imperceptible. By further increasing the deflection, the second damage was 
observed in the GFRP ribs due to excessive compressive strain (Fig. 6b), where the load level was $69.67 \mathrm{kN}$, corresponding to deflection of $0.62 \mathrm{~mm}$. A hardening stage was registered above deflection of $0.62 \mathrm{~mm}$, and a peak load of $90.03 \mathrm{kN}$ for a deflection of 7.32 $\mathrm{mm}(\approx \mathrm{L} / 68)$ was recorded in the Point $\mathrm{C}$ (Fig. 8d). Above this deflection, the slab entered a structural softening stage and subsequently, the load carrying capacity of the slab decreased smoothly. The slab's load carrying capacity at the ultimate deflection (about $30 \mathrm{~mm}, \approx \mathrm{L} / 17$ ) was approximately $44.5 \mathrm{kN}$, which is about $50 \%$ of the peak load.

According to the measured slip in Fig. 9d, a nonlinear increment of the slip started to be measured at force of $88.28 \mathrm{kN}$ and slip of $0.008 \mathrm{~mm}$. At this slip, the deflection in the slab ST2 was recorded equal to $1.89 \mathrm{~mm}$, as shown in Fig. 10b, while compressive damage in the GFRP ribs occurred at deflection of $0.62 \mathrm{~mm}$. This indicates that damage is almost intensified in the connection zone between the ribs and DHCC layer for deflection of 0.62 $\mathrm{mm}$ up to $1.89 \mathrm{~mm}$; therefore, by further increasing the deflection to $1.89 \mathrm{~mm}$, an abrupt increment of the slip was registered.

According to the results indicated in Fig. 11d, a maximum tensile strain of 0.00066 was measured in the GFRP skin (SG1), and a maximum compressive strain of 0.0059 was recorded in the GFRP ribs (SG3). Additionally, the strain distribution across the panel's thickness at mid-span indicated that the specimen ST2 acted in fully composite action up to $0.4 \mathrm{P}_{\max }(36.01 \mathrm{kN})$, semi-composite action at load level of $0.6 \mathrm{P}_{\max }(54.02 \mathrm{kN})$, and noncomposite action at $0.8 \mathrm{P}_{\max }$ and $\mathrm{P}_{\max }$, as shown in Fig. $12 \mathrm{~d}$.

\subsection{Shear loading with span ratio of $\mathbf{0 . 7 7}$}

The loading was arranged to create a shear span ratio of 0.77 , where an inclined compression strut runs from the load to the support through GFRP ribs and foam cores, GFRP skin is loaded as tension tie, and DHCC layer is subjected to top horizontal compressive strut. The main aim of this series of shear tests is to identify shear performance of the hybrid slabs SL1 and SL2, where the possibility of locally buckling failure in the GFRP ribs due to excessive in-plane compressive stress is investigated.

Figs. $8 \mathrm{e}$ and $8 \mathrm{f}$ indicate the response of the slabs under shear loading with a span ratio of 0.77. The specimen SL1 presented an almost linear force-deflection response up to $153 \mathrm{kN}$, when a deflection of $0.1 \mathrm{~mm}$ was recorded in Point B (Fig. 8e). The first damage was observed at load level of $120 \mathrm{kN}$ (Point A in Fig. 8e), due to the loss of contact between the foam and DHCC (Fig. 7a), where its effect on stiffness was ignorable up to Point B. Then, at Point $B$, ply delamination was observed in the GFRP ribs when subjected to in-plane compressive loads, where the load of $151.28 \mathrm{kN}$ and deflection of $0.107 \mathrm{~mm}$ were registered 
(Fig. 7b). By further increasing the deflection, an increase of load was observed in the slab, where a peak load of $228.07 \mathrm{kN}$ and deflection of $4.89 \mathrm{~mm}(\approx \mathrm{L} / 102)$ were measured at Point $\mathrm{C}$, and splitting cracks started to be appeared on the top surface of the DHCC layer along the alignment of the GFRP ribs (Fig.7d). In the hardening stage (branch BC in Fig. 8e), the delaminated area in the GFRP ribs locally buckled (delamination buckling) and the damage propagated at the connection zone between the GFRP ribs/DHCC layer, as shown in Fig. 7c. It is worth stating that various parameters could contribute for the occurrence of the delamination and buckling in the GFRP ribs, such as thickness of GFRP ribs, distance between GFRP ribs, height of GFRP ribs, and distance between load positions and supports. Above the deflection of $4.89 \mathrm{~mm}$, the specimen SL1 entered a softening structural behavior and subsequently, the deterioration was intensified at the connection zone between GFRP ribs/DHCC layer and at the connection between the GFRP rib/GFRP skin (see Fig. $7 e)$. According to the obtained experimental results, shear cracks were appeared in the foam cores due to large residual deflection (Fig. 7f), where an almost constant residual load carrying capacity of about $110.39 \mathrm{kN}$ was registered at deflection of $35.72 \mathrm{~mm}(\approx \mathrm{L} / 14)$, which is about $48 \%$ of the load corresponding to Point $\mathrm{C}$.

As shown in Fig. 9e, it is indicated that an abrupt increment of the slip was recorded at a force/deflection corresponding to force of $210.38 \mathrm{kN}$ and slip of $0.057 \mathrm{~mm}$. The relationship between the deflection and slip in Fig. 10c indicates that, due to existence of an internal support redundancy of the connectors which can be attributed to the increased sectional area of DHCC dowels, the deterioration of the shear connection was reduced smoothly up to deflection of $30 \mathrm{~mm}$ in the softening behaviour of the slab.

According to the results shown in Fig. 11e, a maximum tensile strain of 0.0277 was registered in the GFRP rib (SG 2). After occurrence of local damages in the GFRP ribs, causing the nonlinear damage to propagate in the GFRP ribs and skin corresponding to force of $170 \mathrm{kN}$, the tensile strains measured in the GFRP ribs of the specimen SL1 exceeded the ultimate strains recorded in the direct tensile tests carried out with the specimens extracted from these components of the slab (see Table 2). The efficiency of shear connectors of Slab 1 was evaluated by the strain distribution across the panel's thickness at mid-span under shear loading with span ratio of 0.77 . Regarding the indicated strain distribution across the slab's thickness in Fig. 12e, the specimen SL1 acted in semicomposite action up to $0.6 \mathrm{P}_{\max }(136.84 \mathrm{kN})$, and a non-composite action was observed for further increasing of the load level up to $0.8 \mathrm{P}_{\max }(182.40 \mathrm{kN})$ and $\mathrm{P}_{\max }$.

The force versus deflection response of Slab 2 under shear loading with a span ratio of 0.77 is shown in Fig. 8f. According to the experimental results obtained herein, like other tested hybrid slabs, an almost linear force-deflection response was measured for the specimen 
SL2, where the force was registered equal to $140.04 \mathrm{kN}$ at deflection of $1.14 \mathrm{~mm}$ in Point B (Fig. 8f). Despite recording no severe damages in the linear response of the slab, the first damage was observed due to loss contact between the DHCC layer and foam cores, where the load of $95.54 \mathrm{kN}$ and deflection of $0.63 \mathrm{~mm}$ were recorded in Point A (Fig. 6a). However, this damage had no significant effect on the stiffness of the slab. Nonlinear damage in the specimen SL2 was mainly propagated due to excessive compressive strain in the GFRP ribs (Fig. 6b) when subjected to a force of $140.04 \mathrm{kN}$ at deflection of $1.14 \mathrm{~mm}$ in Point B (Fig. 8f). By further increasing the deflection, a hardening behavior was observed in the slab, where a peak load of $170.95 \mathrm{kN}$ and deflection of $5.37 \mathrm{~mm}(\approx \mathrm{L} / 93)$ were measured at Point $\mathrm{C}$. In the hardening stage (branch $\mathrm{BC}$ in Fig. 8f), some splitting cracks began to form on the top surface of the DHCC layer along the alignment of the GFRP ribs (Fig. 6d). Above $5.37 \mathrm{~mm}$ of deflection, a softening structural behavior was observed in the specimen SL2, where an almost constant residual load carrying capacity of about $97.75 \mathrm{kN}$ was registered at deflection of $22.50 \mathrm{~mm}(\approx \mathrm{L} / 22)$, which is about $57 \%$ of the peak load. Moreover, shear cracks were formed in the foam cores resulted from large residual deflection (Fig. 6e). Recording large residual deflection in the hybrid slabs in spite of various damages demonstrates that the linear-elastic nature of the GFRP components of the slab has affected the global behavior of the slab.

Concerning the measured slip in Fig. 9f, an abrupt increment of the slip was begun to be recorded at force of $119.62 \mathrm{kN}$ and slip of $0.005 \mathrm{~mm}$. By beginning of softening behavior in the specimen SL2 at deflection of $5.37 \mathrm{~mm}$, the connection between the DHCC layer and GFRP ribs was lost (Fig. 6c) and subsequently, large values of the slip were registered, as shown in Fig. 10c.

With respect to the results indicated in Fig. 11f, during the deflection hardening stage of the slab SL2, the compressive strain in the GFRP rib (SG3) increased significantly from 0.000011 to 0.0015 due to the deterioration of the shear connection between the ribs and DHCC layer, and a maximum tensile strain of 0.00077 was measured in the GFRP skin (SG1). Therefore, tensile strains in the GFRP ribs and skin did not experience strains more than the ultimate strains recorded in the direct tensile tests carried out with the specimens extracted from these components of the slab.

As shown in Fig. 12f, the strain distribution across the panel's thickness was used to depict the efficiency of the indented shear connectors to provide composite action in the hybrid slab 2 under shear loading with a span ratio of 0.77 . Regarding the obtained results, the specimen SL2 acted in fully composite action up to $0.8 \mathrm{P}_{\max }(136.76 \mathrm{kN})$, whereas at load level of $P_{\max }$, the slab acted in non-composite action. 
In general, according to the experimental results, the provided stiffness at the GFRP ribs/DHCC layer connection significantly affected the global behavior of the hybrid slab under shear loading, including force, deflection, and slip responses. Thus, to approach a profound assessing of the provided stiffness at the connection zone, combining of force versus deflection response and force versus slip response of each slab was indicated in Fig. 13. OriginLab software was used to present the results in Fig. 13 [16]. With respect to the results depicted in Figs. 13a to 13f, regardless of type of loadings and span ratios, hybrid slabs were loaded linearly without experiencing any severe damage. During this stage, small values of slip and mid-span deflection were registered. After occurrence of damage in the GFRP ribs due to excessive compressive strains or delamination buckling phenomenon, a nonlinear stage began in the hybrid slabs, considering a hardening behaviour. As shown in Fig. 13, during the nonlinear stage, abrupt increments of deflection and slip were recorded by increase of force, such that a linear relationship was found between the increment of slip and deflection.

Fig 13. Three-dimensional plots of the force along variations of deflection and slip for specimens of: a) SS2; b) ST2; c) SL2; d) SS1; e) ST1; f) SL1

\section{Efficiency of the proposed hybrid sandwich panels}

In order to assess the efficiency of the proposed hybrid sandwich panels, an analytical approach was used. The accuracy of these equations to predict the force versus deflection of hybrid slabs was demonstrated in $[5,10,11,17]$. In order to evaluate the efficiency of the proposed hybrid slabs, this system was compared with two other sandwich panel systems including: 1) Simple sandwich panel with two GFRP skins placed on top and bottom with shear stresses transferred by an intermediate foam core placed in the middle of the two skins; 2) GFRP sandwich panel with internal ribs, where two GFRP skins are used as top and bottom skins and shear stresses are transferred by the GFRP ribs together with the foam cores (the shear stress is mainly transferred by the GFRP ribs). A schematic figure of the slabs and slab's component placement is indicated in Table 3, which is used to assess the shear performance of the slabs submitted under a load condition with a span ratio of 2 .

\section{Table 3. Used different types of sandwich panels in the numerical simulations}

Some approximations are implemented to obtain the load-deflection response of the slabs. Equations (1) and (2) are used to consider both flexural and shear deformations in the slabs under a three-point bending test. The differences between Equations (1) and (2) are related 
to the mechanism of transferring shear stresses between skins through foam cores or GFRP ribs. In Equation (1), the shear stress is transferred by the foam core, while in Equation (2), the GFRP ribs transfer shear stresses between the top and bottom skins,

$$
\begin{gathered}
\Delta=\frac{\left(P L^{3}\right)}{(48 E I)_{\text {Total }}}+\left(\frac{P L}{4 K G A}\right)_{\text {Foamcore }} \\
\Delta=\frac{\left(P L^{3}\right)}{(48 E I)_{\text {Total }}}+\left(\frac{P L}{4 K G A}\right)_{\text {Rib }}
\end{gathered}
$$

where $P$ is the applied load, $L$ is the span of the beam, $E I$ is the flexural stiffness that was calculated using transformed cross-section analysis (in calculation of this value, effects of all the materials such as foam cores, DHCC layer, GFRP ribs, GFRP skin, etc. were considered), $G$ is the shear modulus of the GFRP ribs, and $A$ is the cross section of the ribs. The flexural stiffness of the panels is also estimated analytically by using transformed crosssection analysis. Table 4 lists the calculated flexural and shear stiffness for different slabs.

\section{Table 4. Calculated flexural and shear stiffness for composite slabs}

It is worth stating that in the GFRP sandwich panel with internal ribs and simple GFRP sandwich panel, the thickness and material properties of GFRP sheets and foam cores were assumed as equal to hybrid slabs. For instance, the thickness of the GFRP skin in Slab 1 was equal to $3 \mathrm{~mm}$, therefore, both the GFRP sandwich panel with internal ribs and the simple GFRP sandwich panel, the thickness of the GFRP faces was considered equal to 3 $\mathrm{mm}$ in the analytical equations. Moreover, the thickness of the ribs in the GFRP sandwich panel with internal ribs was considered equal to $6 \mathrm{~mm}$. As no slip was observed between the GFRP skin, GFRP rib and foam cores during the experimental tests, it was postulated that the GFRP faces and ribs had a perfect bond with the foam cores. It is worth mentioning that using equal thicknesses for the slab's components of other typical sandwich panels may not be correct, and such thicknesses should be designed and then, comparison should be executed. However, the obtained results provide a general idea of the structural performance of the hybrid slabs.

According to Fig. 14a, using the hybrid Slab 1 led to an increase of $21.6 \%$ in stiffness, when compared to the sandwich panel with internal rib. This stiffness was $68.7 \%$ greater than the simple sandwich panel stiffness. Additionally, concerning analytical results obtained in Fig. $14 \mathrm{~b}$, using the hybrid Slab 2, an increase of $20.4 \%$ in terms of stiffness was measured, when comparing the hybrid panel and the sandwich panel with internal rib. Furthermore, the stiffness in hybrid Slab 2 was $31.9 \%$ higher than the stiffness in the corresponding simple 
sandwich panel. Regarding the results depicted in Fig. 4, it is revealed that using hybrid sandwich panels provided an increase on the stiffness and, consequently, the load carrying capacity for a certain deflection was higher.

\section{Fig 14. The obtained force-deflection responses for: a) Slab 1; b) Slab 2}

\section{Conclusions}

In this paper, six hybrid slabs with different lengths were fabricated and experimentally tested. In order to guarantee an effective load transfer between the DHCC layer and GFRP skin, capable of providing high load carrying capacity, indented shear connectors were used in the GFRP ribs.

The shear performance of the hybrid slabs was assessed by executing experimental monotonic shear tests with span ratios in the range of 0.77 to 2.00 , aiming to get more detailed results on the shear behaviour of the indented connectors used at the GFRP rib/DHCC interface. The following conclusions are collected, based on the relevant observations:

1. The stiffness at the GFRP ribs/DHCC layer connection strongly influenced the load carrying capacity, the flexural stiffness and the absorbed energy of the tested hybrid panels.

2. By considering the force value measured at the last testing stage as the residual load carrying capacity, regardless of shear span ratios, large residual load carrying capacity was registered in the post peak response, of an average of $45 \%$ and $50 \%$ of the peak load for Slab 1 and Slab 2, respectively.

3. A linear relationship was found between the increments of slip and deflection, when an overall nonlinear behaviour began in the slab.

4. The damages observed in the tested slabs showed that they did not experience a sudden failure due to tensile rupture, which is confirmed by the fact that GFRP skin layers remained almost intact. On the opposite, during load application, several damages were localized at different positions of the slabs.

5. Occurrence of delamination buckling in the GFRP ribs led to greater compressive strains than the determined ultimate strains.

6. The maximum height of the GFRP ribs with thickness of $6 \mathrm{~mm}$ should be limited to 160 $\mathrm{mm}$. Beyond this height, delamination buckling is prone to occur in the GFRP ribs.

7. Regarding the obtained results, it is concluded that the thickness and height of the GFRP ribs, and the shear span ratios affected the damage sequences of the hybrid slabs. 
8. The slip values measured in the hybrid slabs show that the indented shear connectors provided a good mechanical anchorage between the GFRP ribs and the DHCC layer in the hybrid slabs under shear loading. This mainly results from the larger sectional area of the DHCC dowel and subsequently, more efficiency of fiber bridging action of hybrid PAN fibers within the reinforced mortar.

9. With respect to the analytical results, the GFRP ribs were the structural component with highest influence on the stiffness, then the highest impact followed by replacing the DHCC layer by the GFRP skin on the top skin.

\section{Declaration of Conflicting Interests}

The author(s) declared no potential conflicts of interest with respect to the research, authorship, and/or publication of this paper.

\section{Acknowledgements}

The study presented in this paper is a part of the research project "RehabGFRP Rehabilitation of Building Floors with Lightweight High Performance GFRP Sandwich Panels", with reference number of PTDC/ECM/113041/2009. Furthermore, the authors honestly appreciate the collaboration of the following labs: PIEP for conducting VARTM process and Department of Civil Engineering of Minho University to perform the tests (Mr. Antonio Matos and Eng. Marco Jorge).

\section{References}

[1]. Hassan T., Reis, E., Rizkalla, S., 2003, "Innovative 3- D FRP Sandwich Panels for Bridge Decks", Proceedings of the Fifth Alexandria International Conference on Structural and Geotechnical Engineering, Alexandria, Egypt, December 20- 22.

[2]. Saoud K.S., Grognec P., 2016, "An enriched 1D finite element for the buckling analysis of sandwich beam-columns", Computational Mechanics, Vol. 57, pp: 887-900.

[3]. T. Keller, E. Schaumann, T. Valle'e, 2007, "Flexural behavior of a hybrid FRP and lightweight concrete sandwich bridge deck", Journal of Composites Part A: Applied Science and Manufacturing, Vol. 38, pp: 879-889.

[4]. A. Fam, T. Sharaf, 2010, "Flexural performance of sandwich panels comprising polyurethane core and GFRP skins and ribs of various configurations", Journal of Composite Structures, Vol. 92, pp: 2927-2935.

[5]. J. He, Y. Liua, A. Chena, L. Dai, 2012, "Experimental investigation of movable hybrid GFRP and concrete bridge deck", Journal of Construction and Building Materials, Vol. 26, 
pp: 49-64.[6]. Charles M. Johnson, Tarek S., Sami H. Rizkalla, 2007, "Behavior of ThreeDimensionally Woven Glass Fiber Reinforced Polymeric Bridge Deck", Composites Research Journal, Vol. 1(2), pp: 27-42.

[7]. Taylor Montgomery Norton, "3D Orthogonal Woven Glass Fiber Reinforced Polymeric Bridge Deck: Fabrication and Experimental Investigation", 2004, Master thesis, North Carolina State University, USA.

[8]. Thanoon W.A., Yardim Y., Jaafar M.C., Noorzaei J., 2010, "Development of interlocking mechanism for shear transfer in composite floor", Journal of Construction and Building Materials, Vol. 24, pp: 2604-2611.

[9]. Alizadeh E., Dehestani M., Navayi Neya B., Nematzadeh M., 2017, "Efficient composite bridge deck consisting of GFRP, steel, and concrete", Journal of Sandwich Structures and Materials, DOI: 10.1177/1099636216688347.

[10]. Mastali M., Valente IB, Barros J.A.O., Gonçalves D., 2015, "Development of innovative hybrid sandwich panels", Journal of Composite Structures, Vol. 133, pp: 476-498.

[11]. Mastali M., Valente IB, Joaquim A.O. Barros, 2017, "Flexural performance of innovative hybrid sandwich panels with special focus on the shear connection behavior", Journal of Composite Structures, Vol. 160, pp: 100-117.

[12]. American Society for Testing and Materials (ASTM) D3039: Standard method for tensile properties of polymer matrix composite materials, 2000.

[13]. American Society for Testing and Materials (ASTM) C365-03. Standard test method for flatwise compressive strength of sandwich cores, 2004.

[14]. Seemann W. H. (1990). U. S. Patent 4,902,215.

[15]. Mastali M., 2016, "Development of innovative hybrid DHCC-GFRP sandwich panels", Ph.D. thesis, Minho University, Portugal.

[16]. http://www.originlab.com/Origin

[17]. Mastali M., Valente IB, Joaquim A.O. Barros, 2016, "Development of innovative hybrid sandwich panel slabs: Advanced numerical simulations and parametric studies", Journal of Composite Structures, Vol. 152, pp: 362-381. 


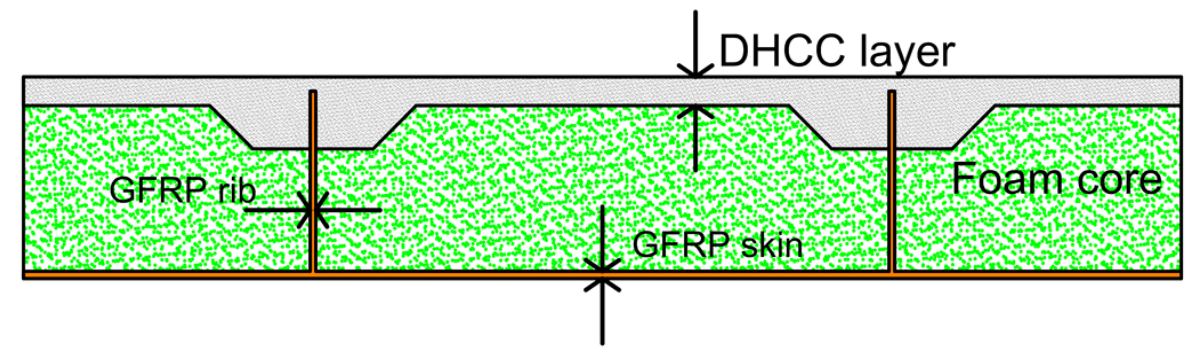

a) Cross section of hybrid sandwich panels

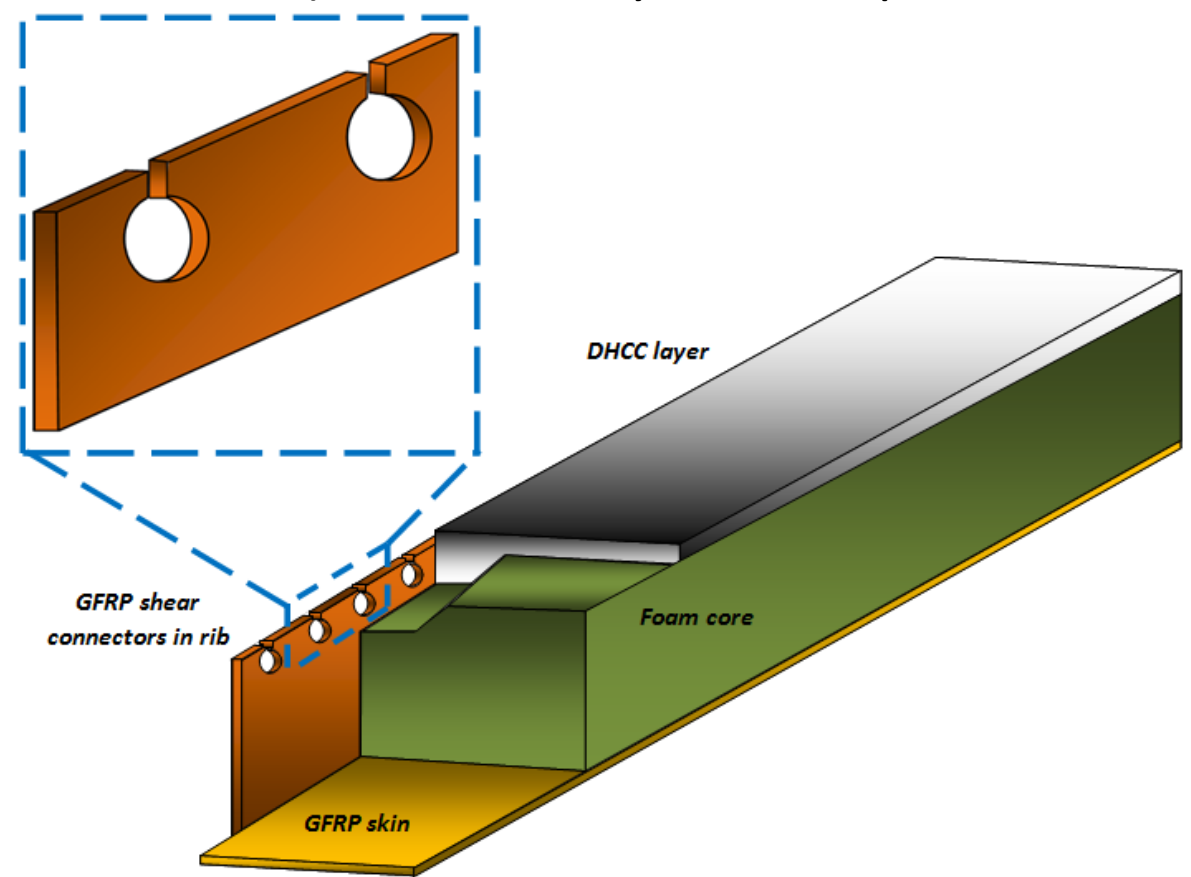

b) 3D view of hybrid sandwich panels

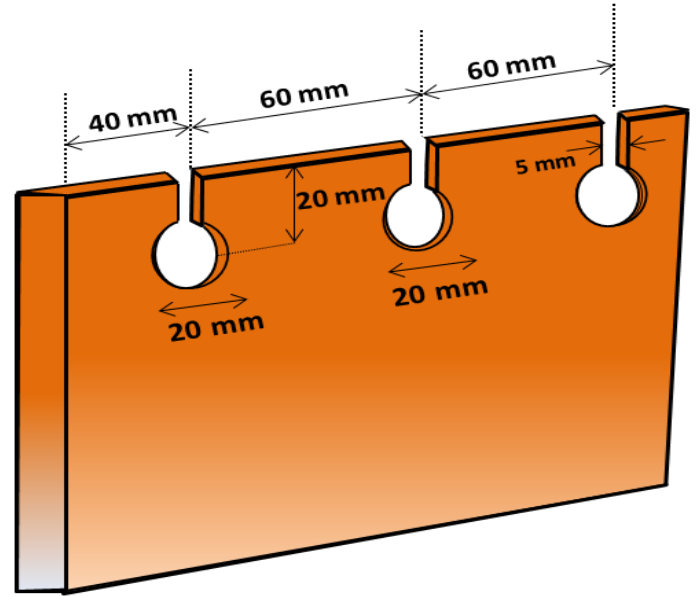

c) Properties of indented shear connectors

Fig 1. Schematic figure of the hybrid sandwich panels 


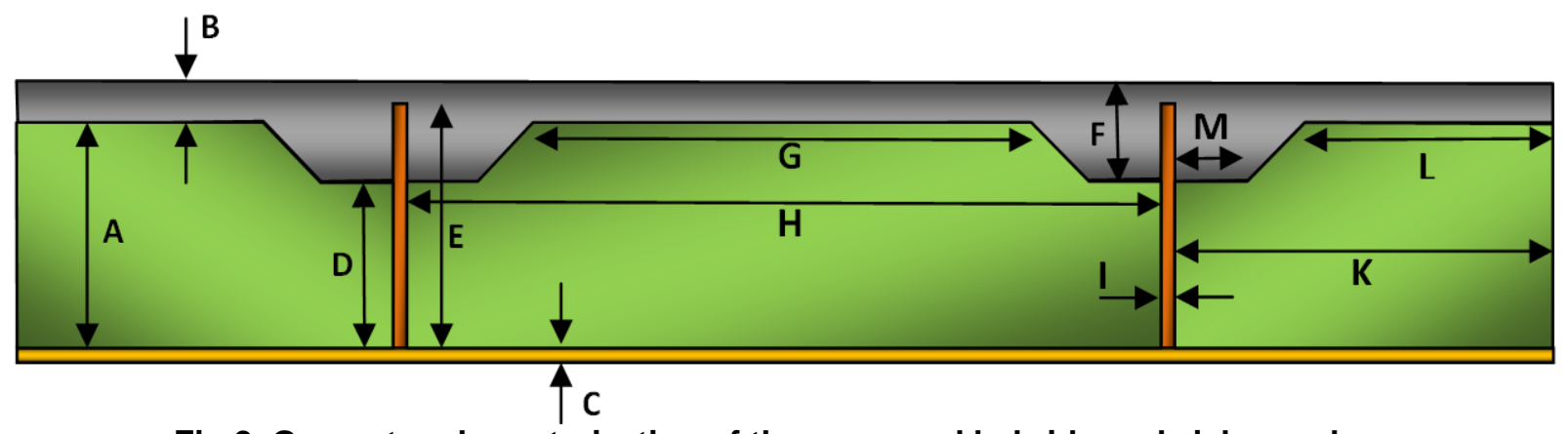

Fig 2. Geometry characterization of the proposed hybrid sandwich panels 


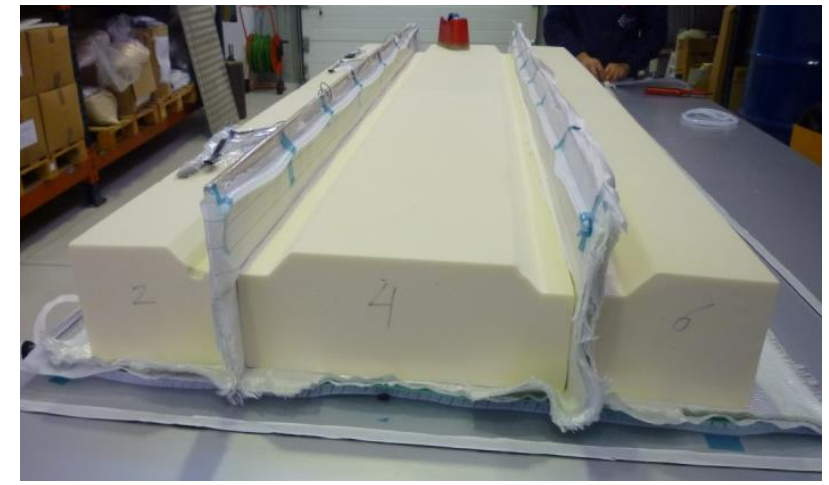

a)

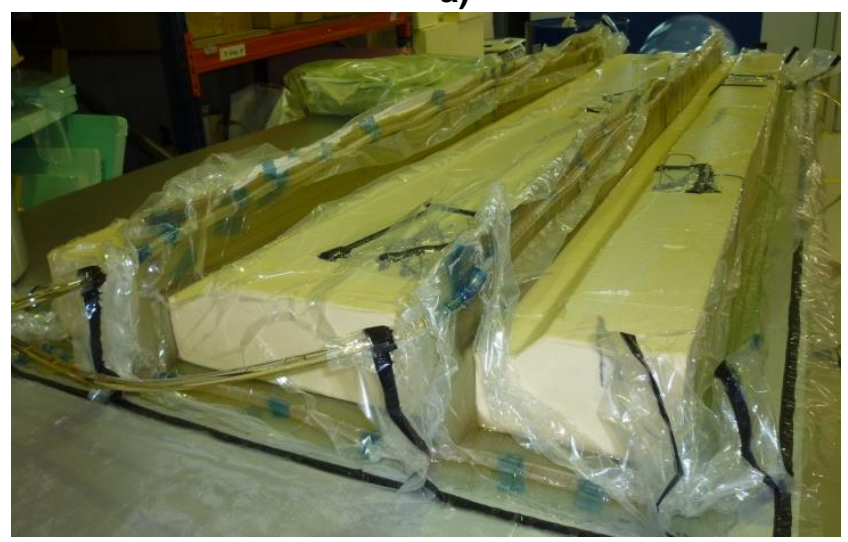

c)

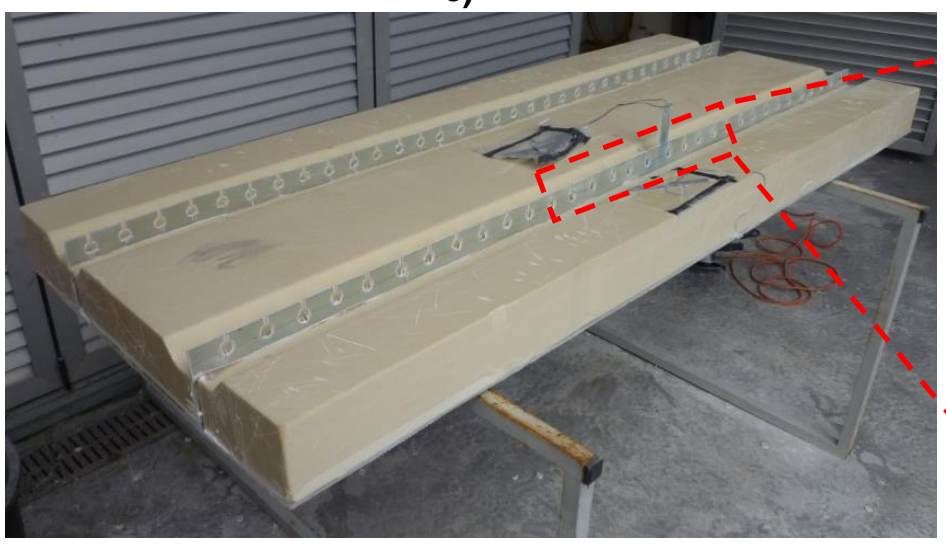

e)
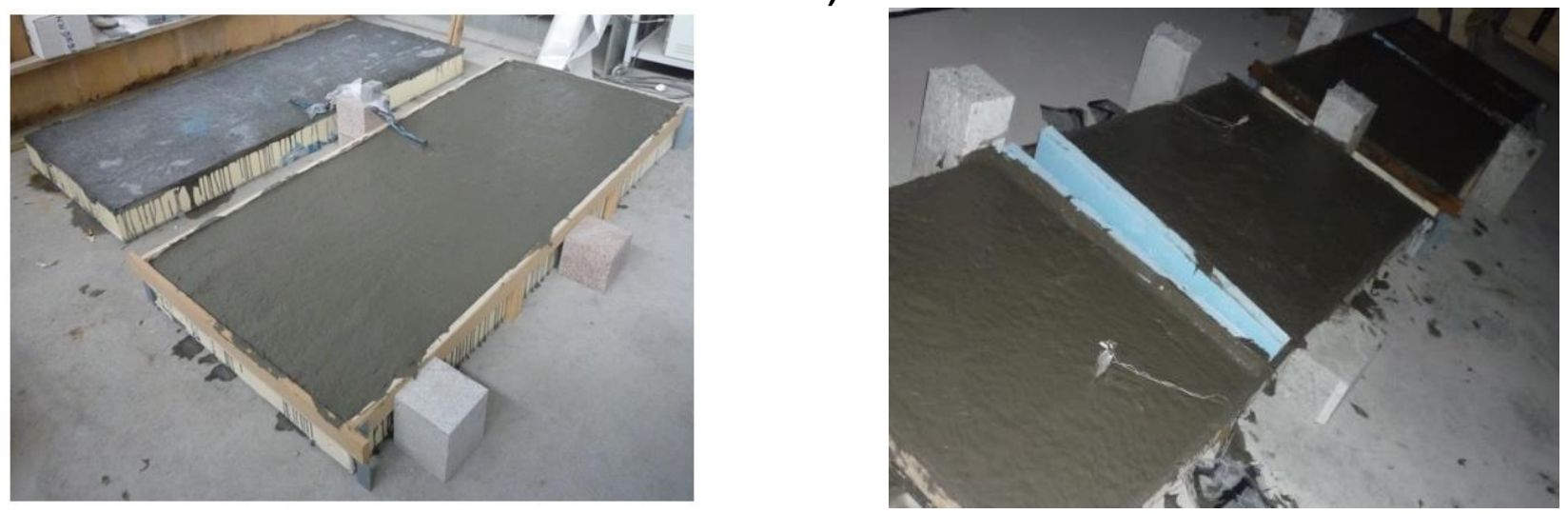

f)

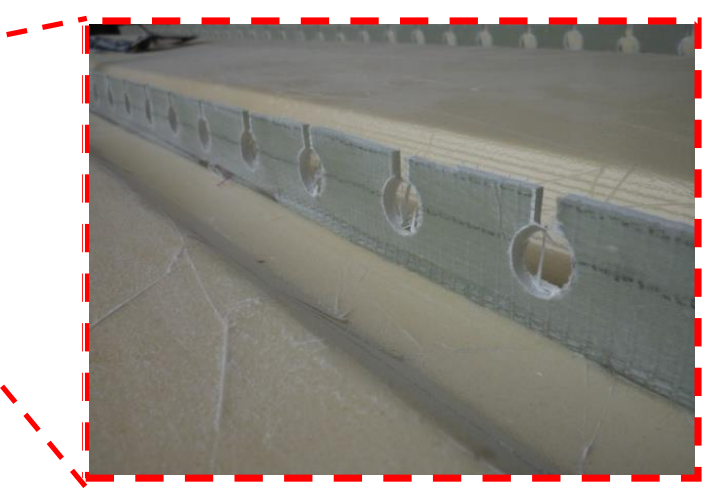

b)

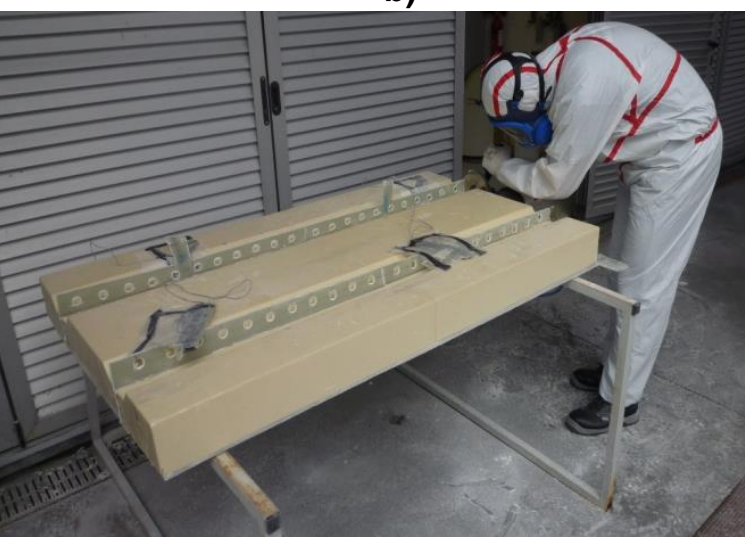

d)

Fig 3. Manufacture process of hybrid slabs: a) fiber layers lay-up; b) sealing the mold; c) resin impregnation; d) trimming; e) creating of shear connectors; f) casting of DHCC layer 


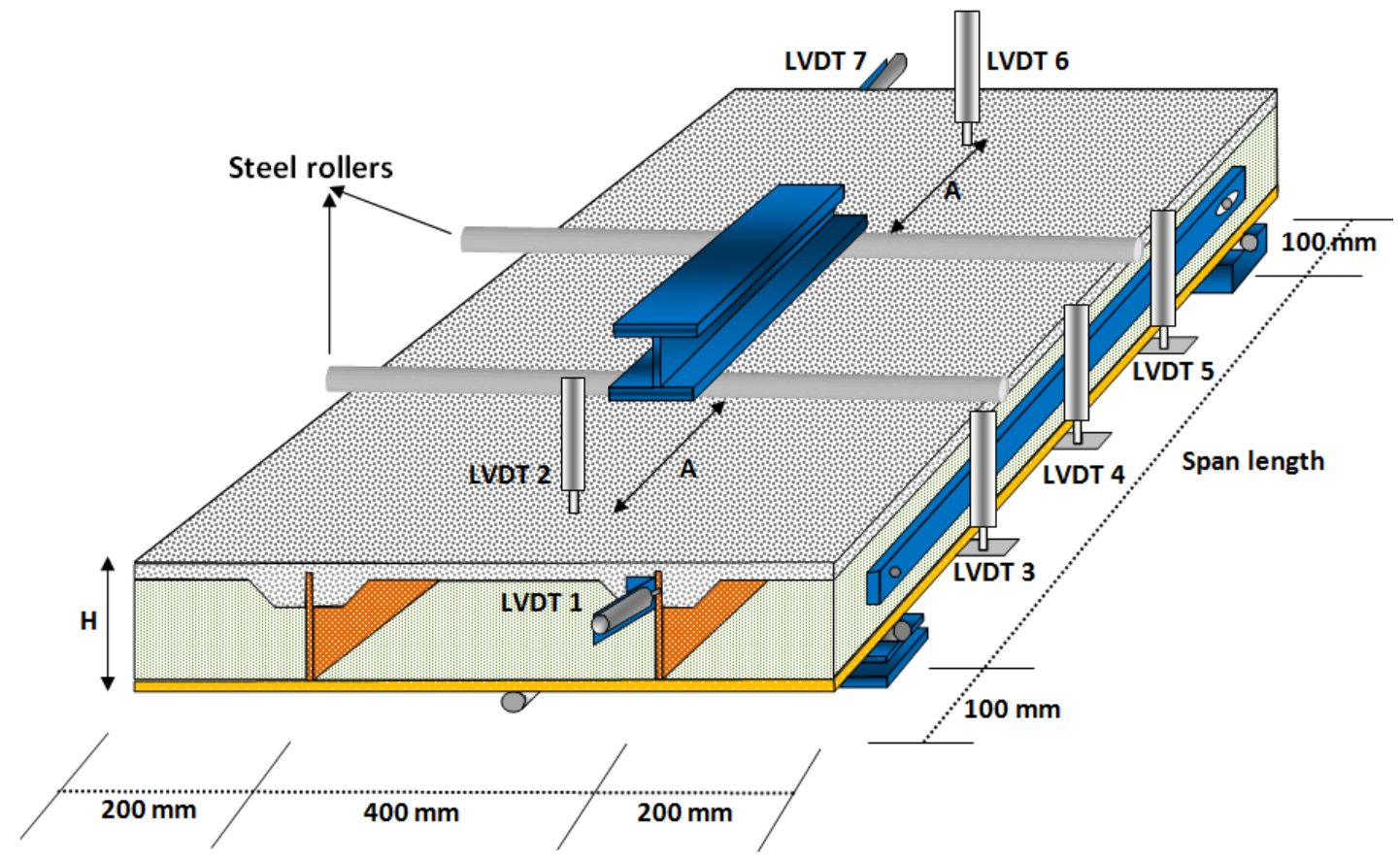

Fig 4. Equipped hybrid slabs for measuring of deflections, slips between GFRP ribs and DHCC layer, and uplifts (vertical deflections) of DHCC layer at support line 


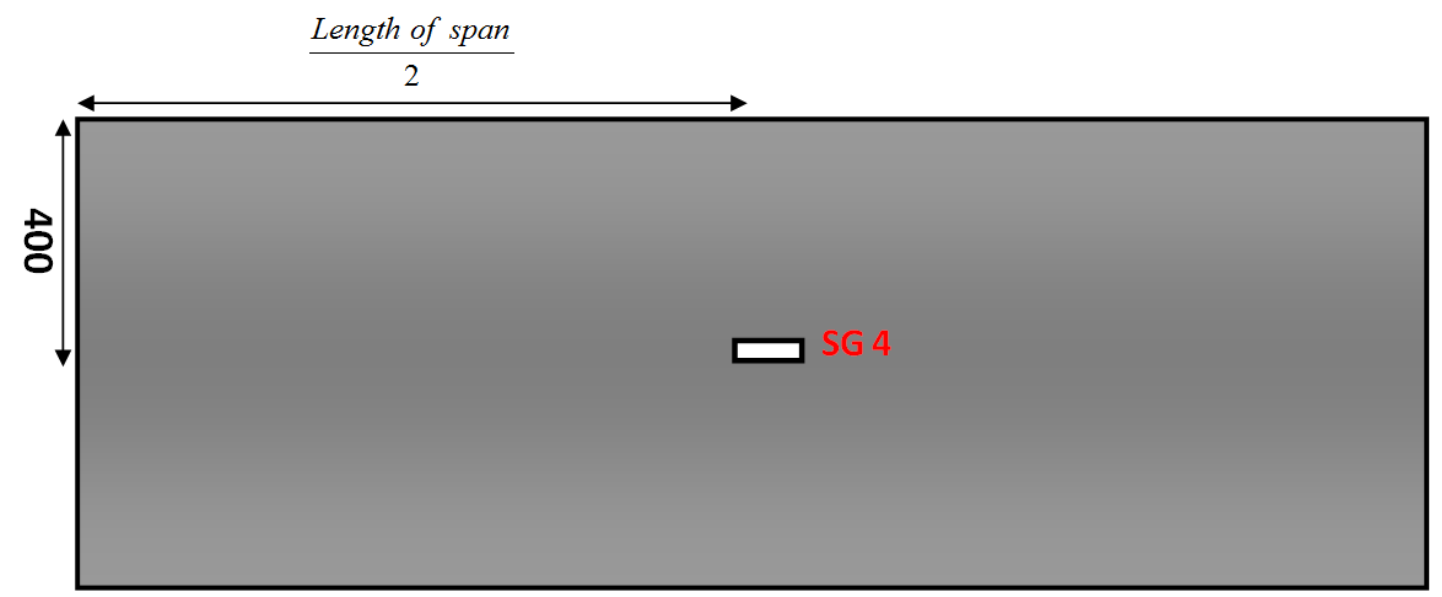

a) Strain gauge 4 (SG 4) on top of DHCC layer

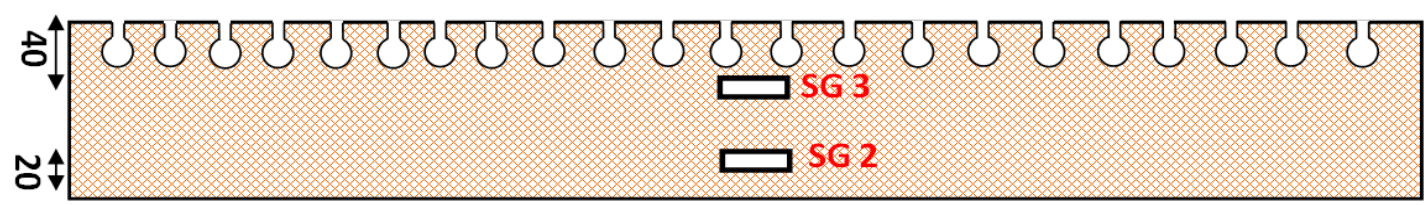

b) Strain gauge 2 (SG 2) and strain gauge 3 (SG3) in the GFRP rib

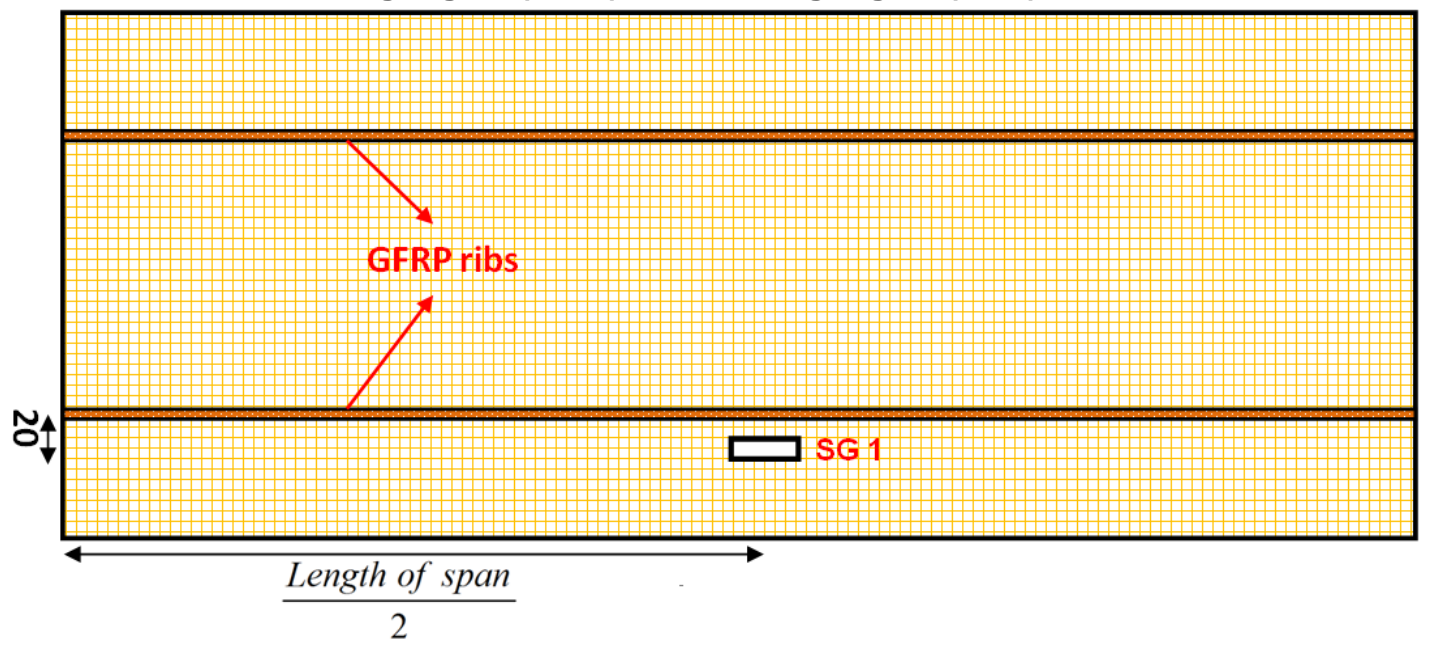

c) Strain gauge 1 (SG 1) on the GFRP skin

Fig 5. Positions of strain gauges in different positions of hybrid sandwich panel (Dimensions in $\mathrm{mm}$ ) 


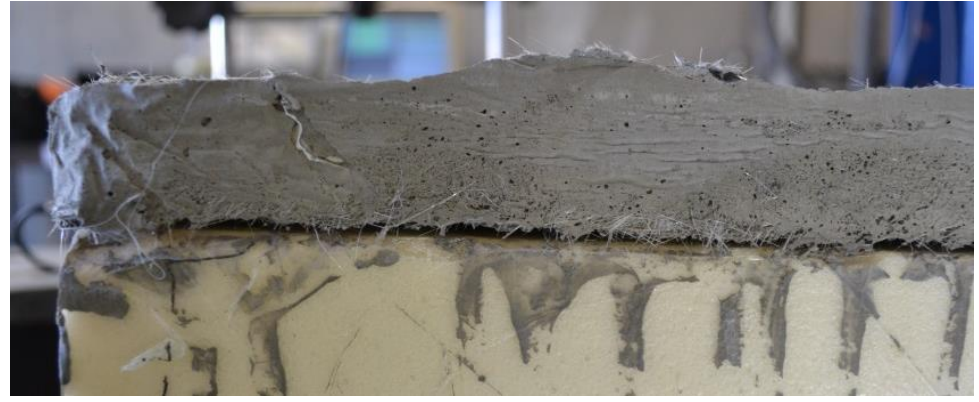

a) Loss of connection between the foam cores and the DHCC layer

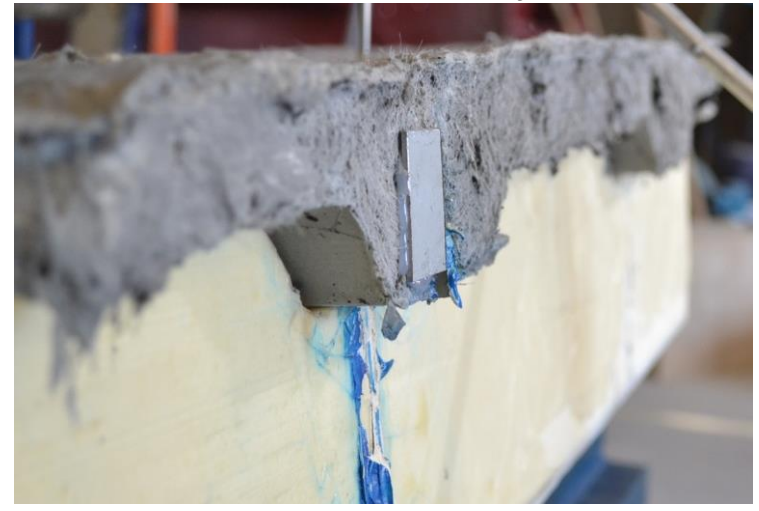

c) Loss bond between the GFRP rib and the DHCC layer

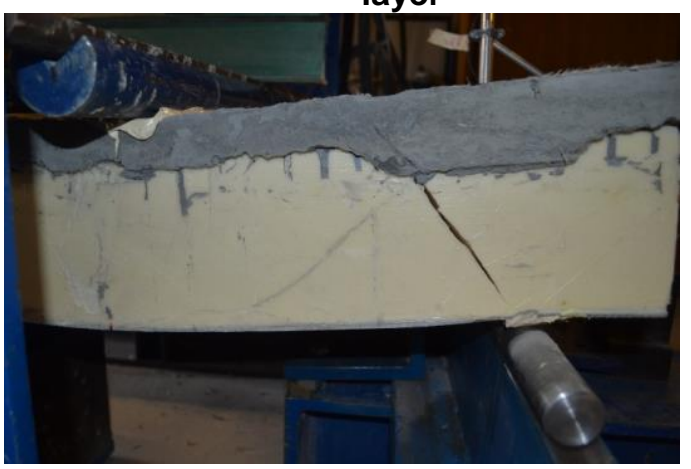

e) Forming shear cracks in foam cores

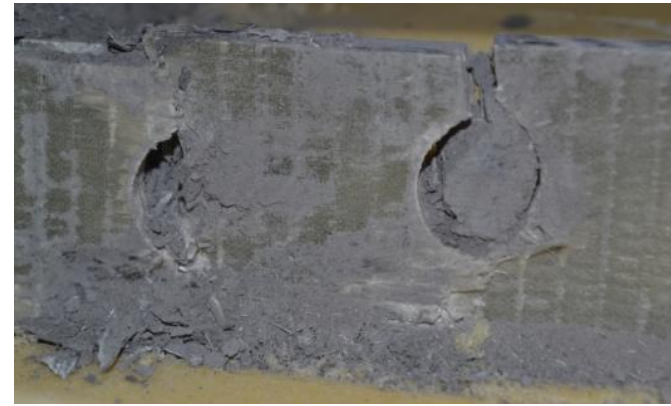

b) Compressive damage in the GFRP rib
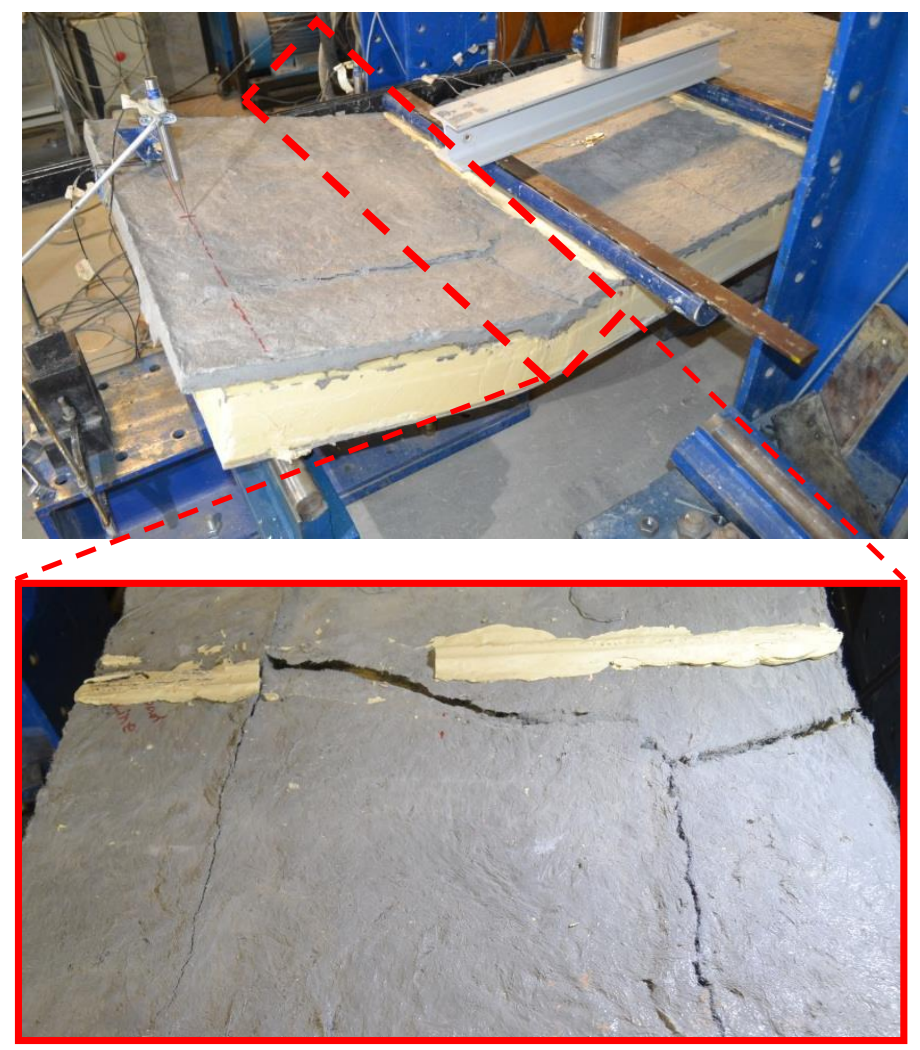

d) Splitting cracks formed on the surface of DHCC layer

Fig 6. Sequences of observed failure modes in specimens SS1, SS2, ST1, ST2, and SL2 


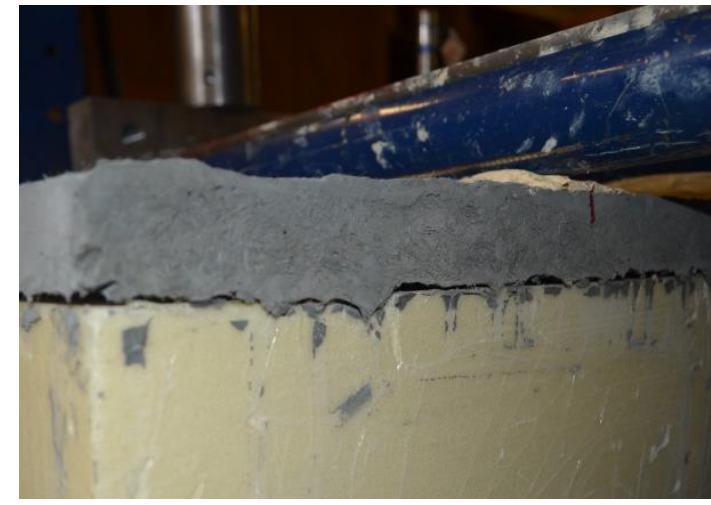

a) Loss of connection between the foam cores and the DHCC layer

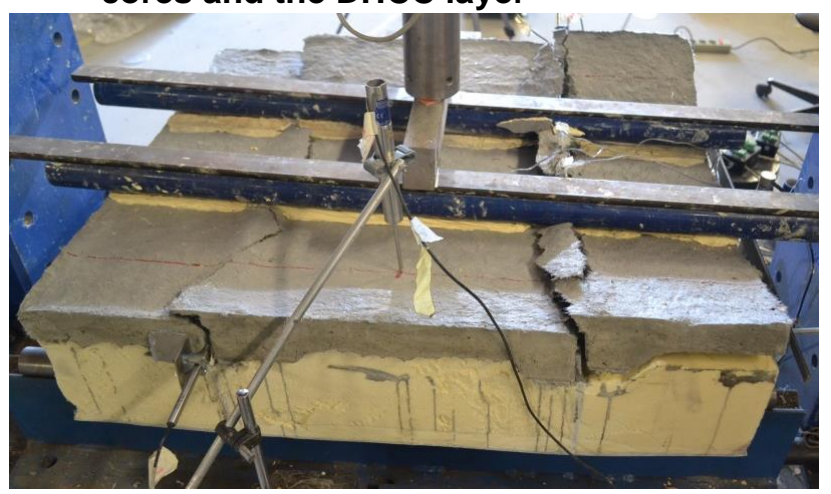

d) Splitting cracks formed on the surface of DHCC layer
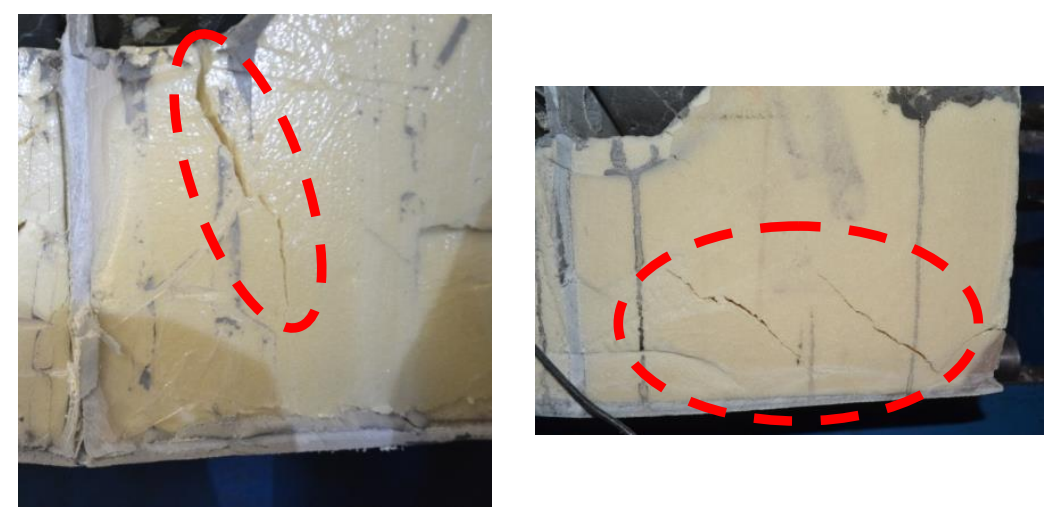

f) Forming shear cracks in the foam cores

Fig 7. Sequences of damages observed in specimen SL1

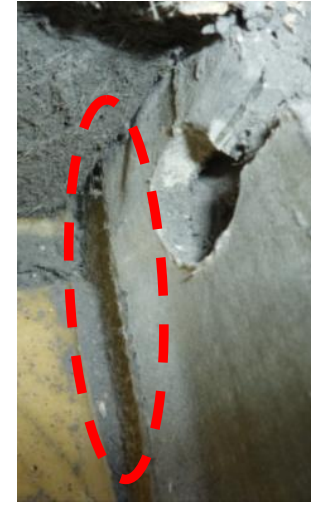

c) Local buckling in the GFRP ribs

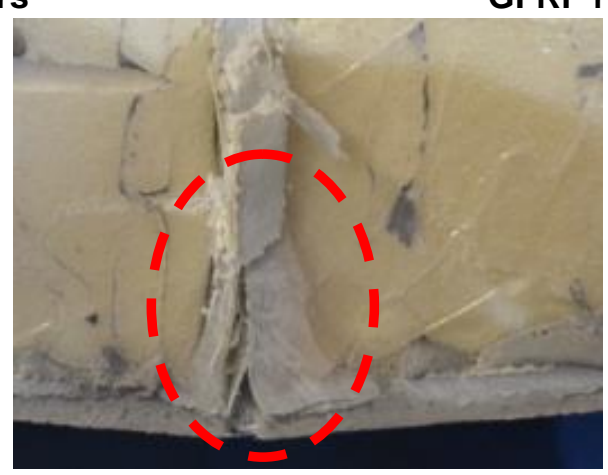

e) Ply delamination of GFRP rib layers at connection zone with GFRP skin 


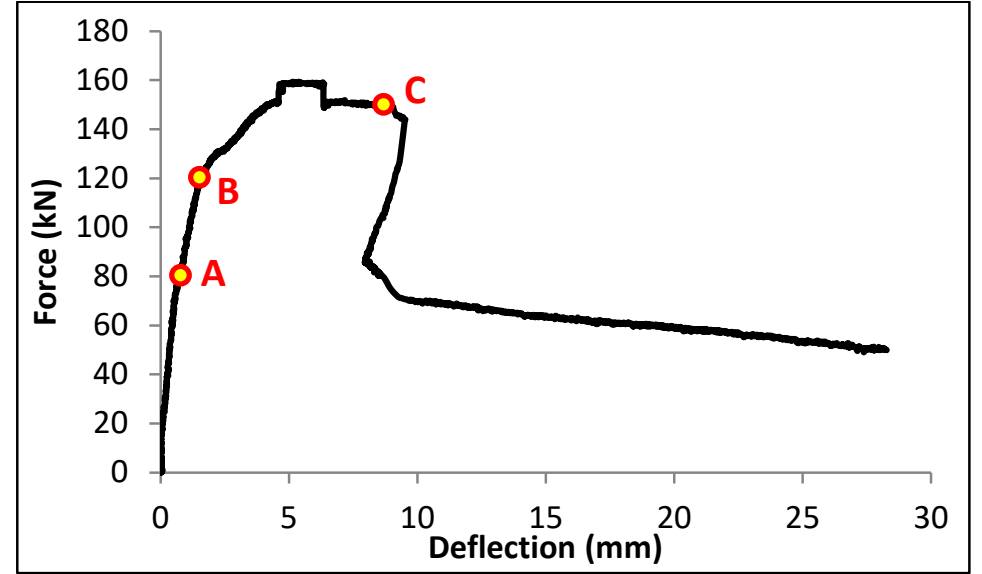

a)

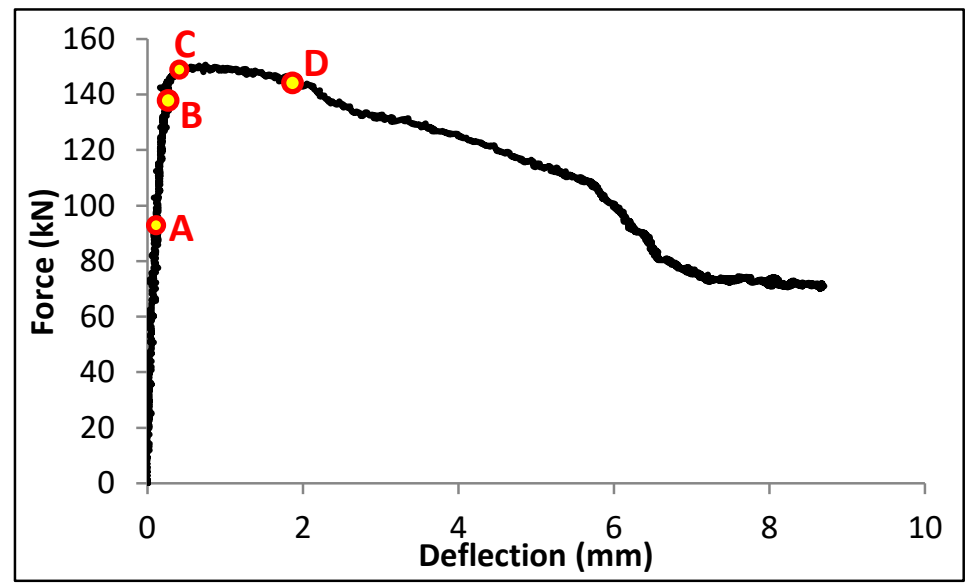

c)

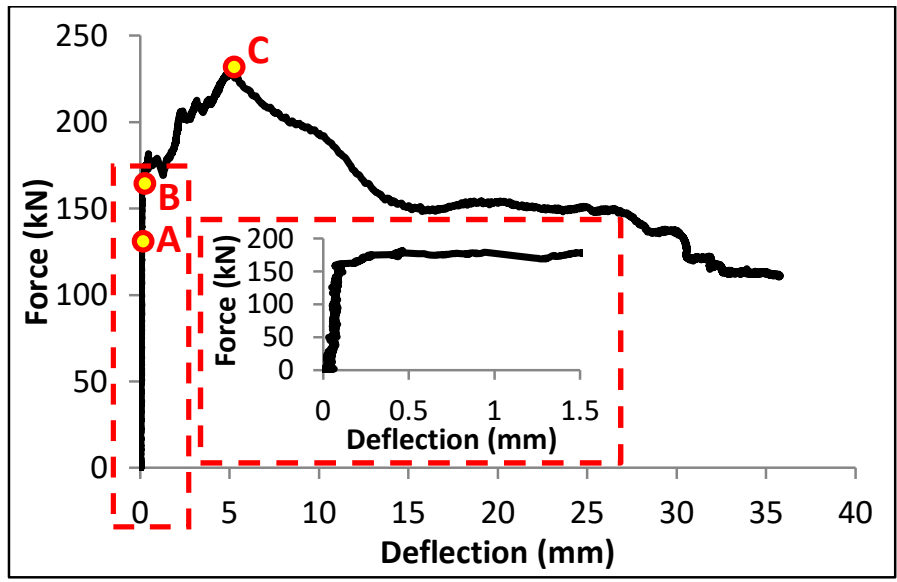

e)

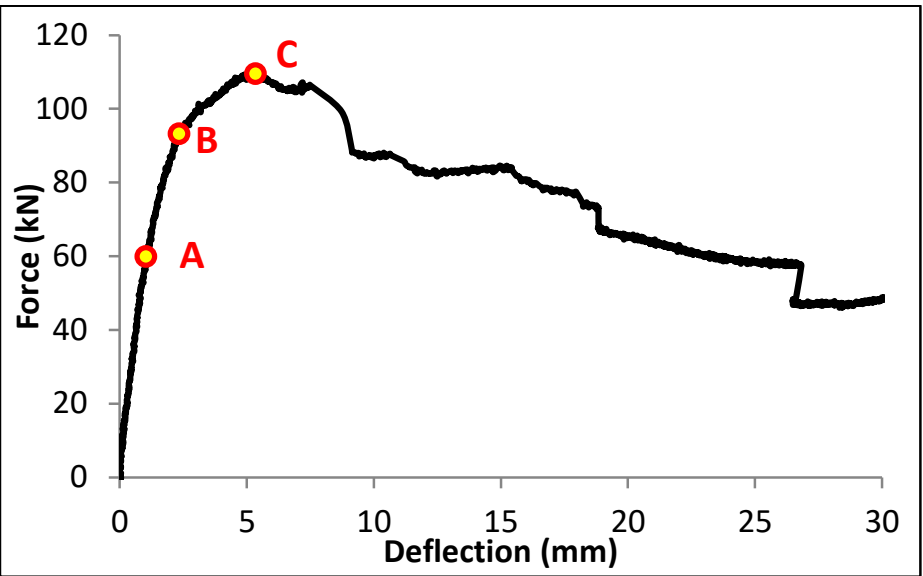

b)

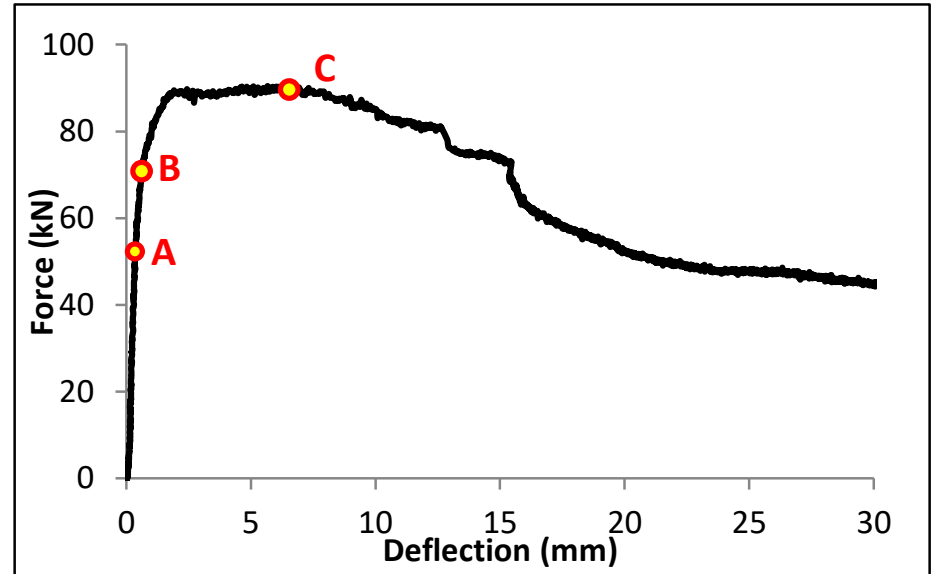

d)

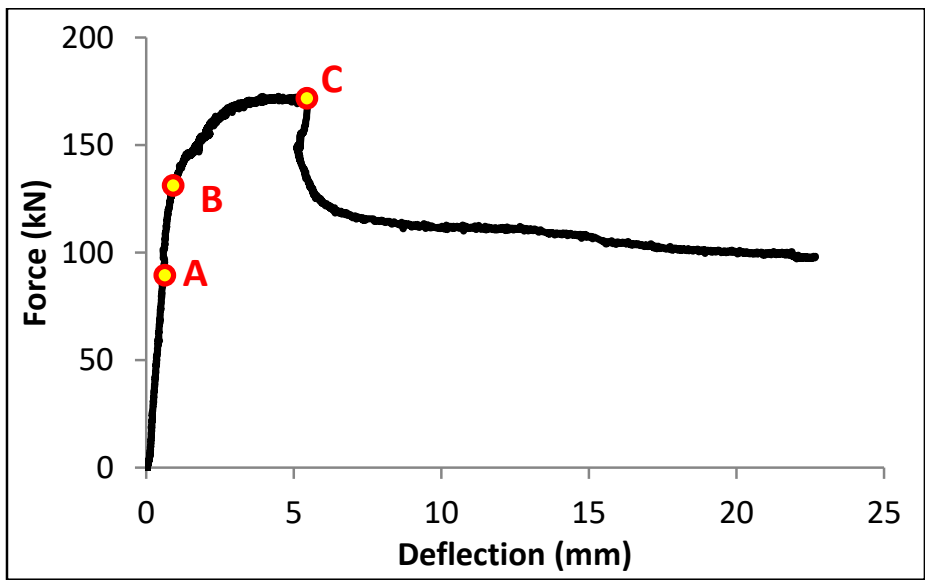

f)

Fig 8. Measured force versus deflection responses for specimens of: a) SS1; b) SS2; c) ST1; d) ST2; e) SL1; f) SL2 


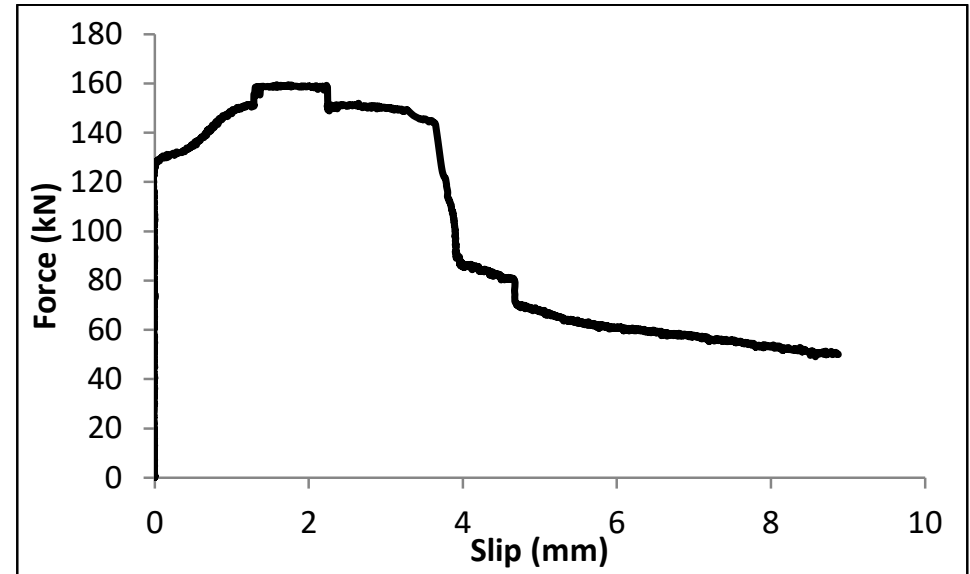

a)

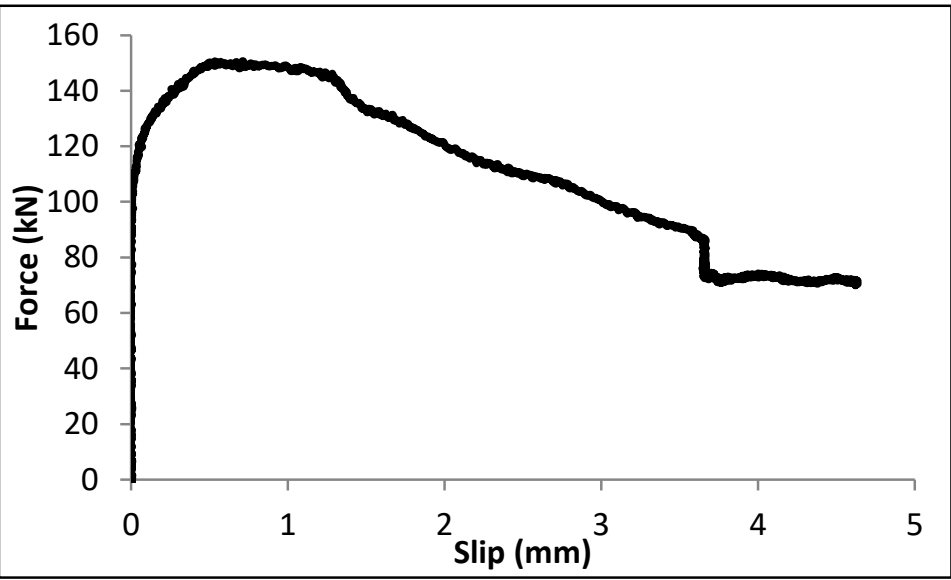

c)

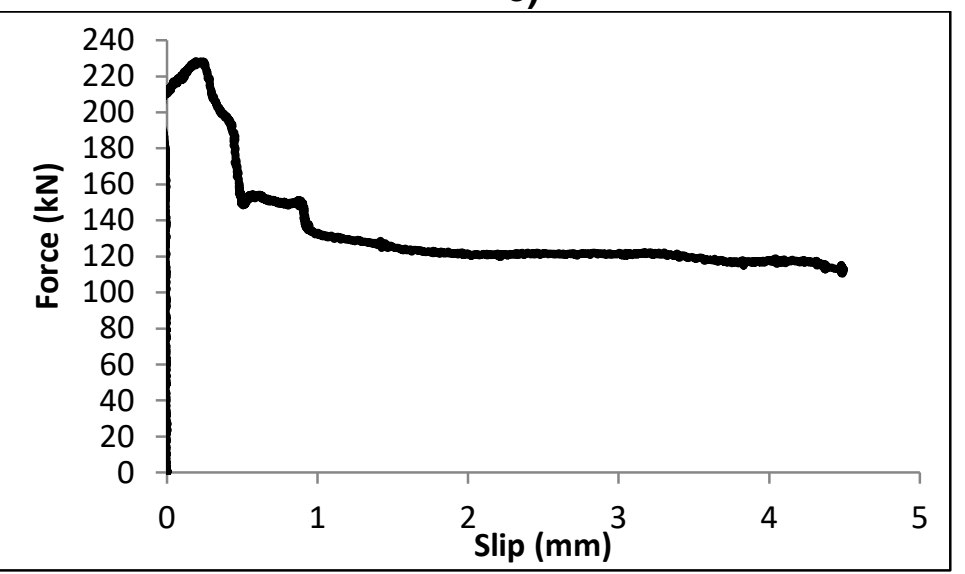

e)

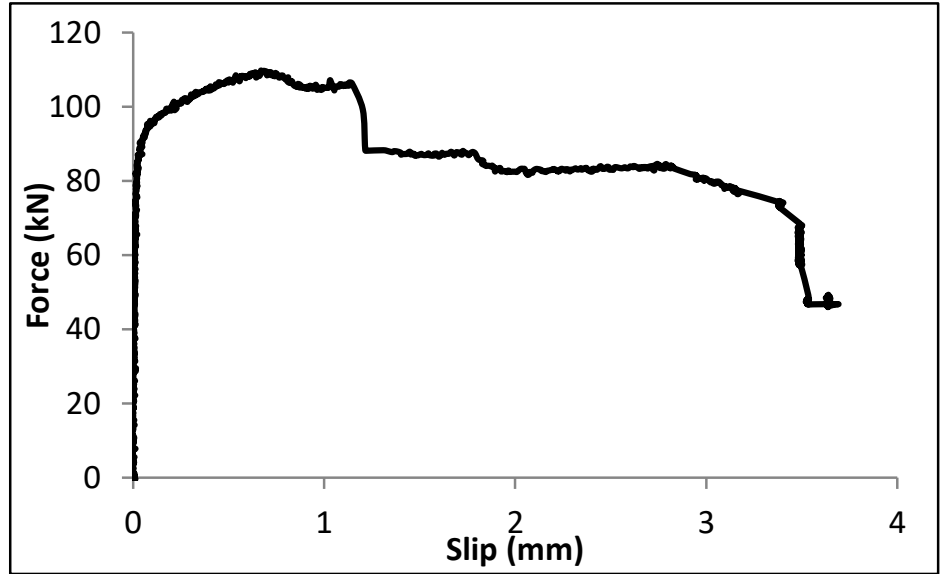

b)

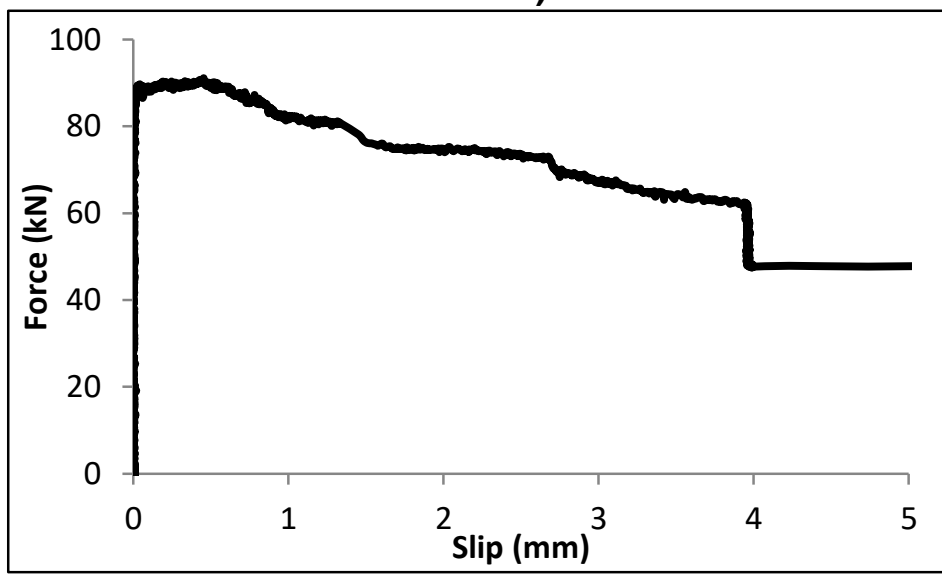

d)

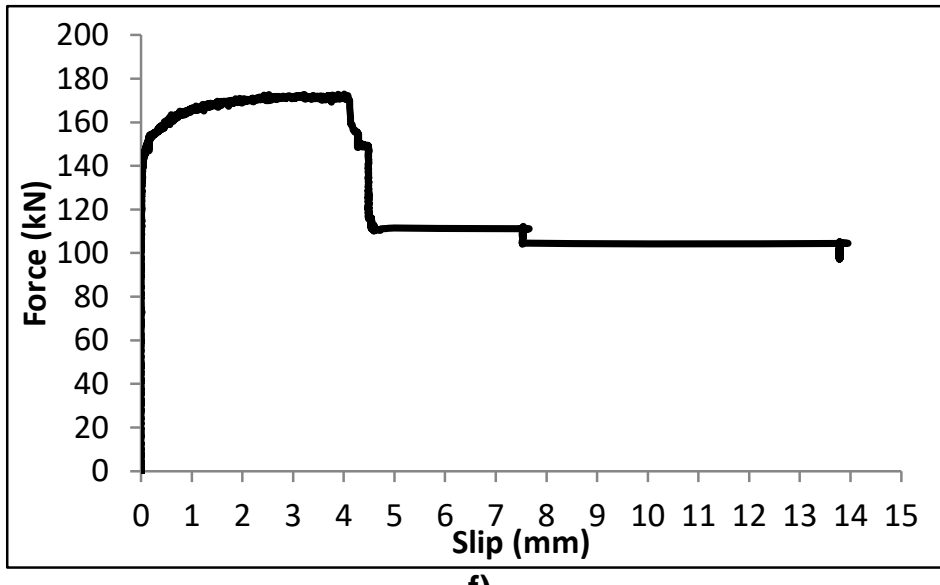

Fig 9. Measured force versus slip responses for specimens of: a) SS1; b) SS2; c) ST1; d) ST2;

e) SL1; f) SL2 


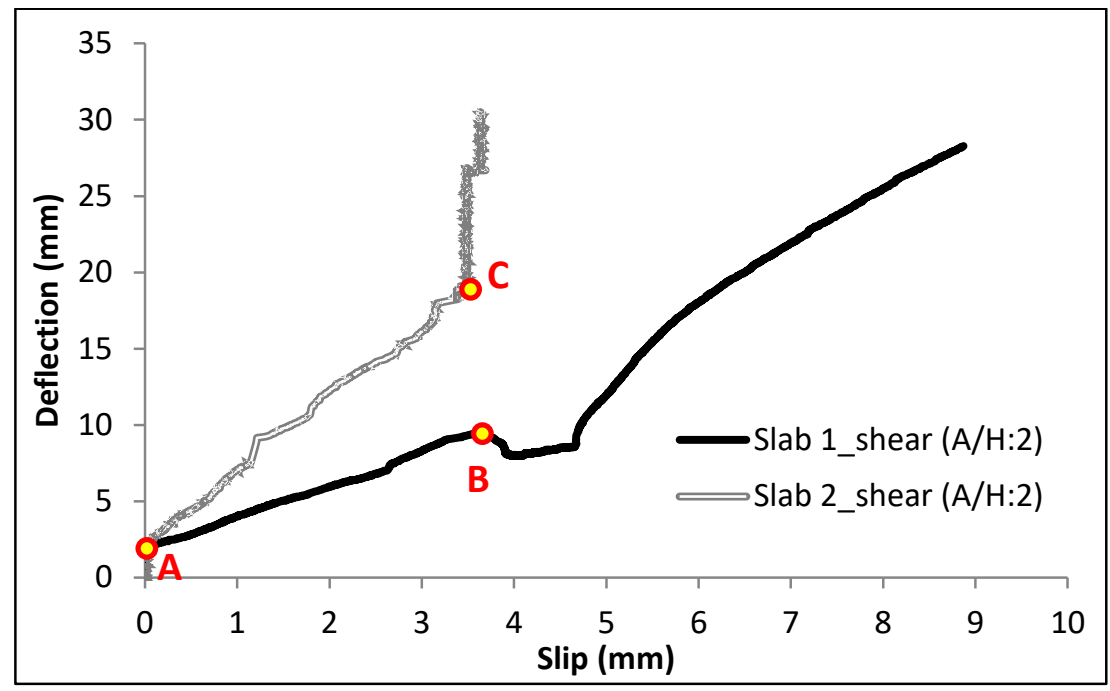

a)

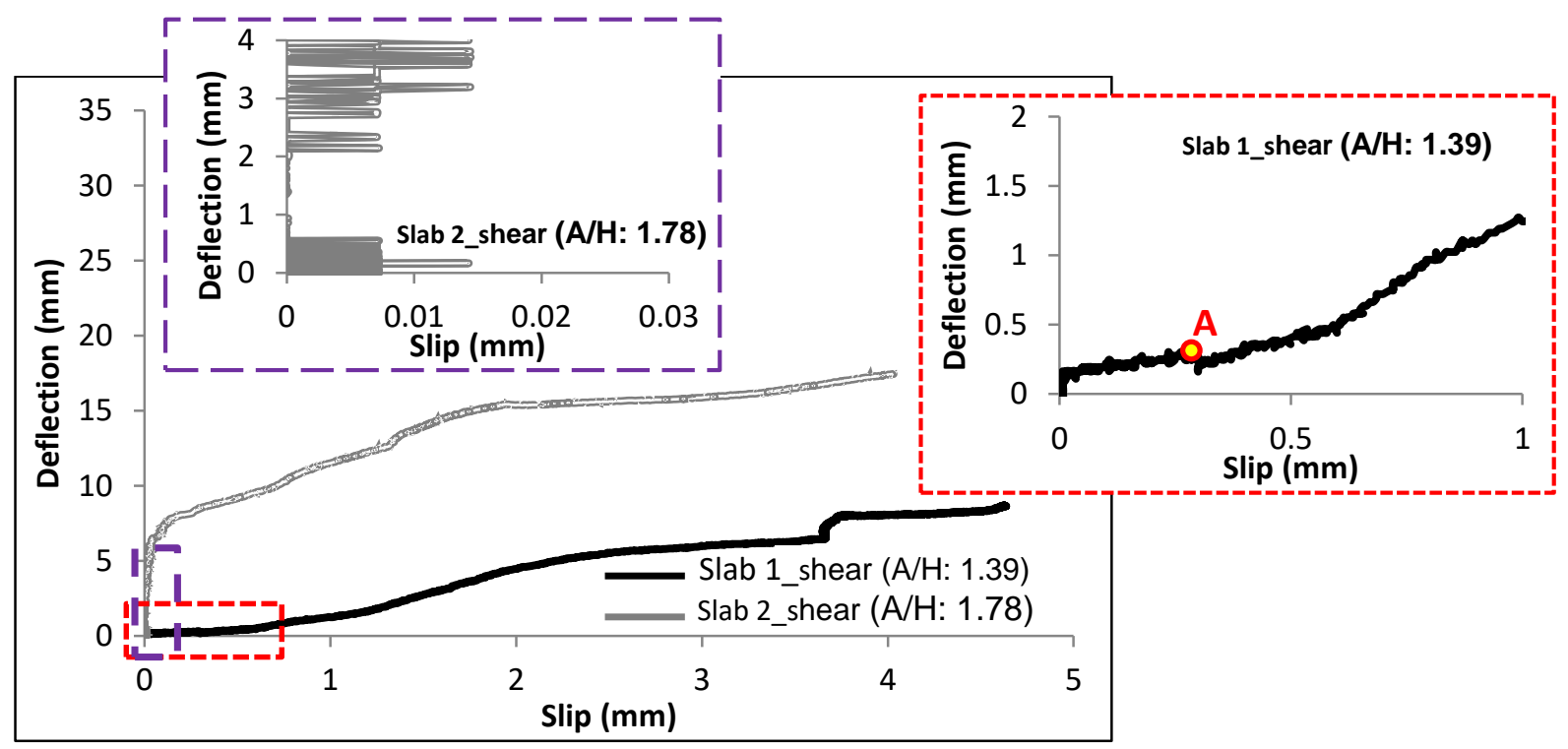

b)

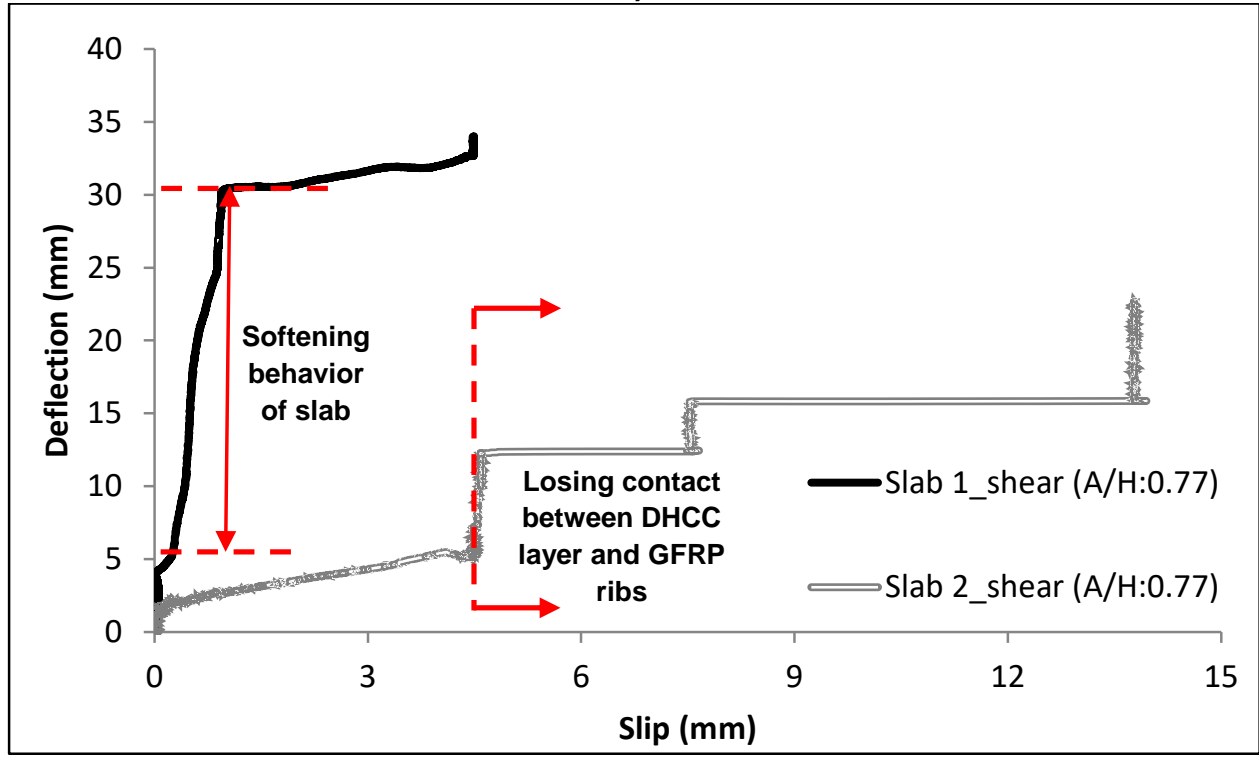

c)

Fig 10. Relationship between deflection versus slip for specimens loaded under shear with span rations of: a) 2; b) 1.39 for Slab 1 and 1.78 for Slab 2; c) 0.77 


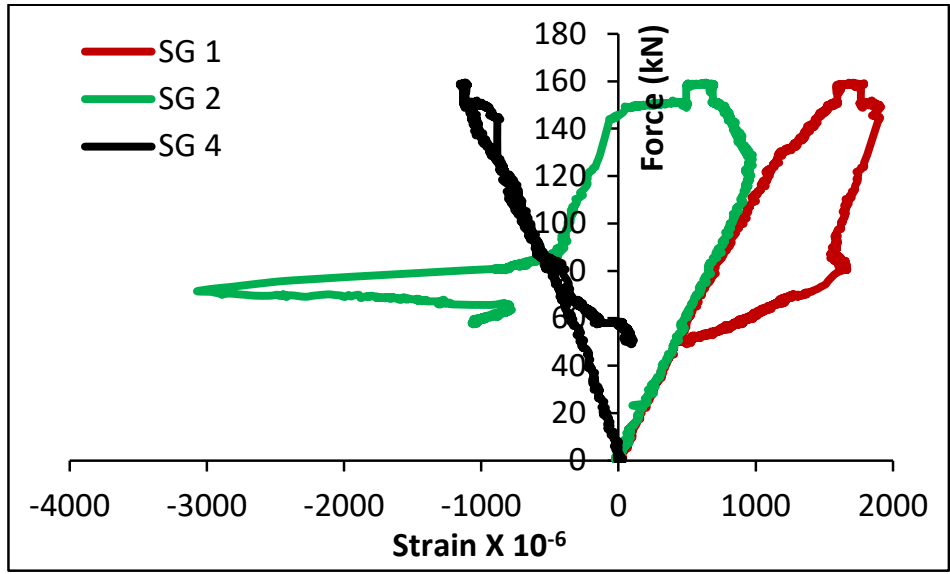

a)

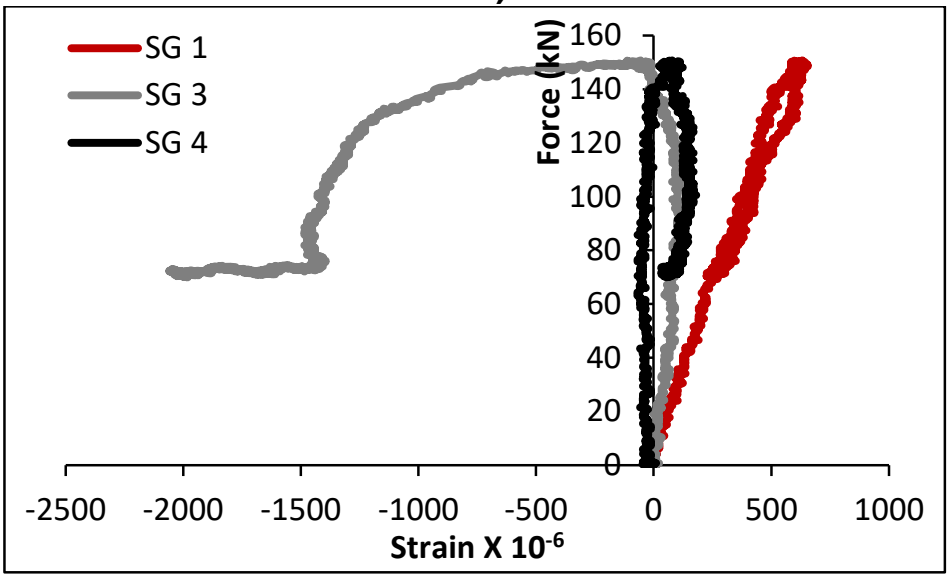

c)

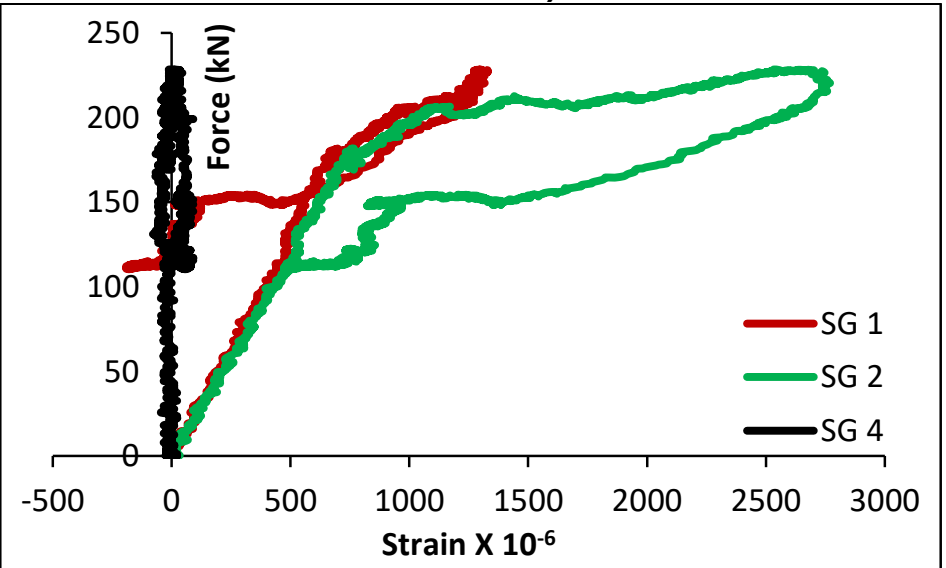

e)

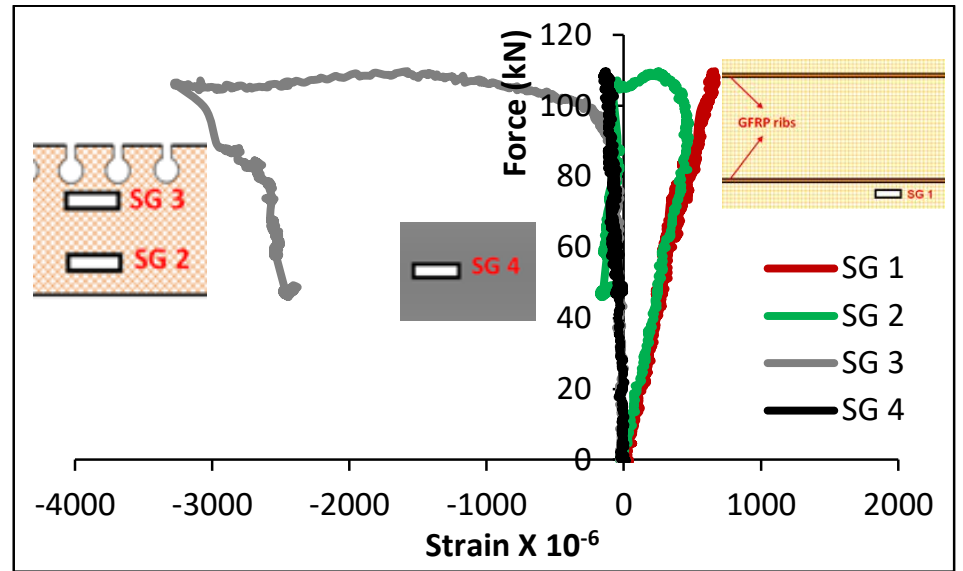

b)

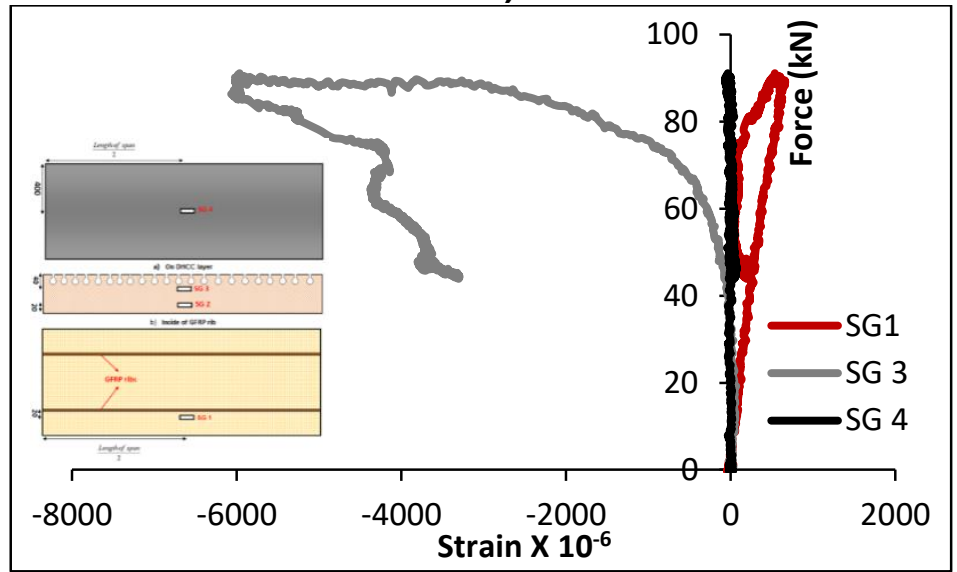

d)

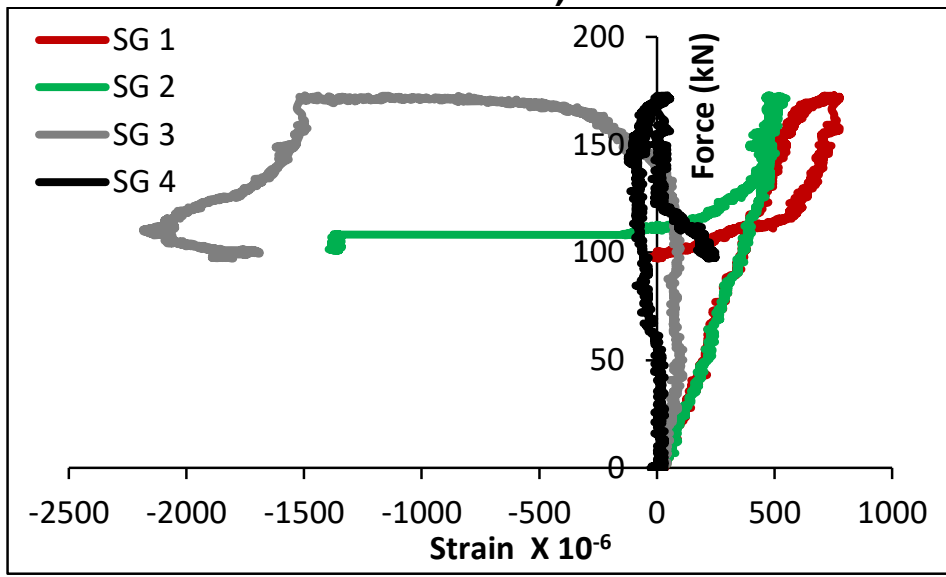

f)

Fig 11. Recorded strain values in different positions for specimens of: a) SS1; b) SS2; c) ST1;

d) ST2; e) SL1; f) SL2 


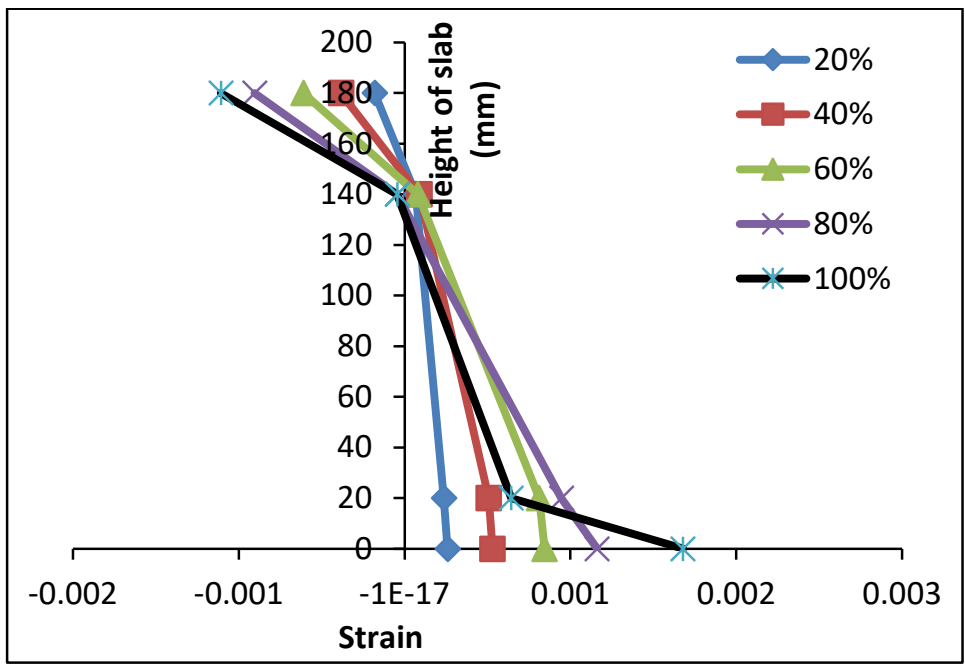

a)

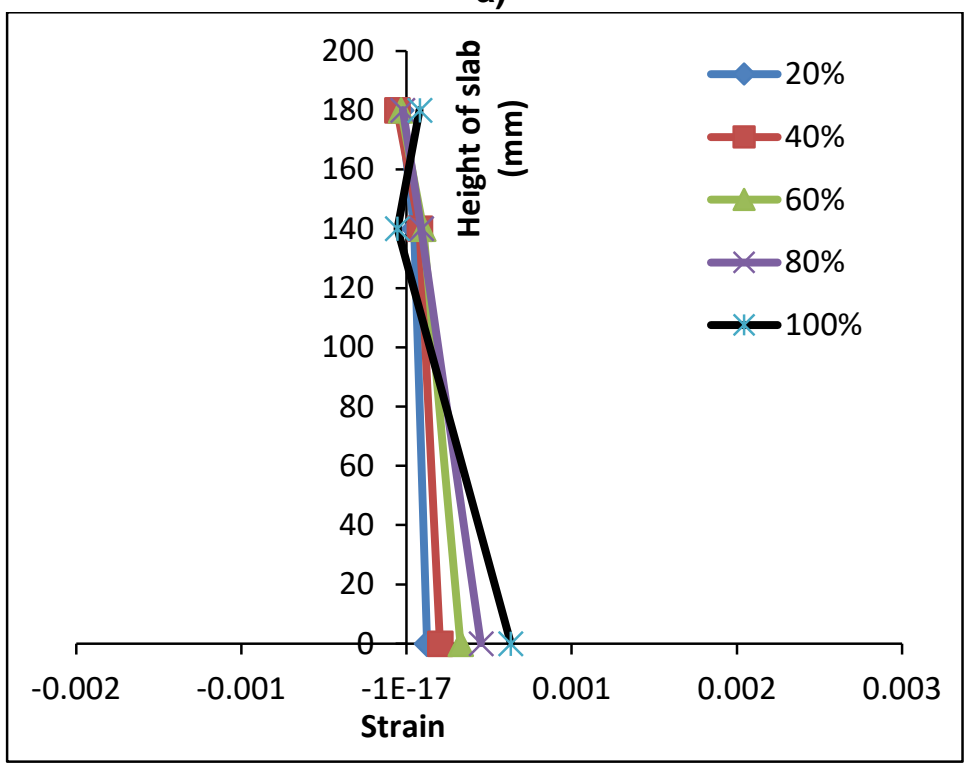

c)

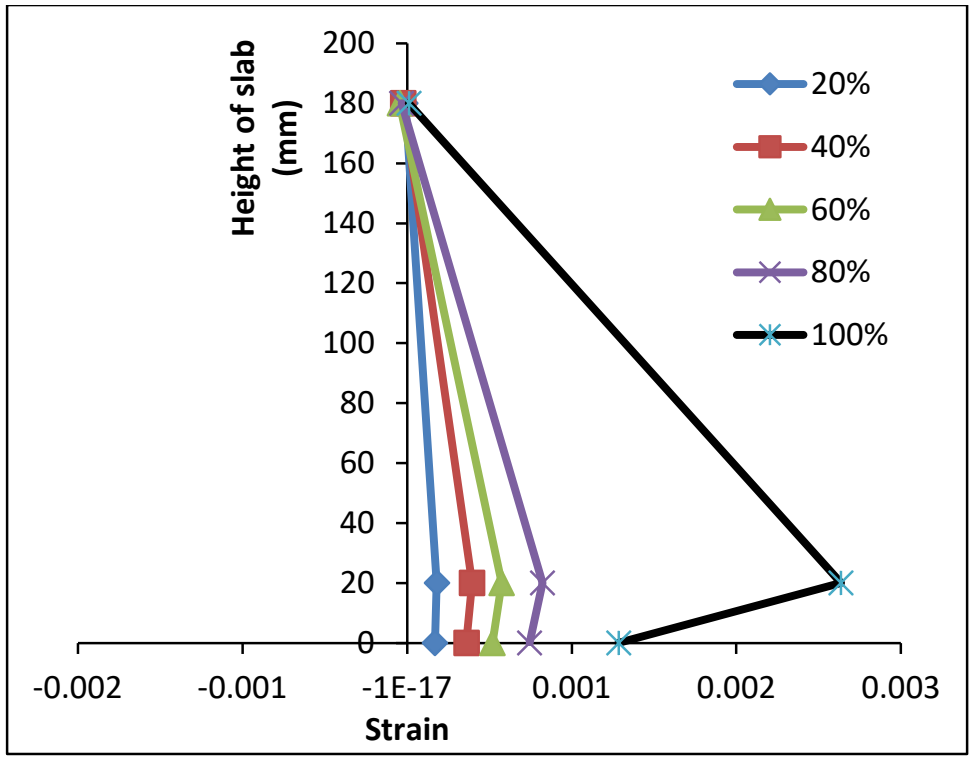

e)

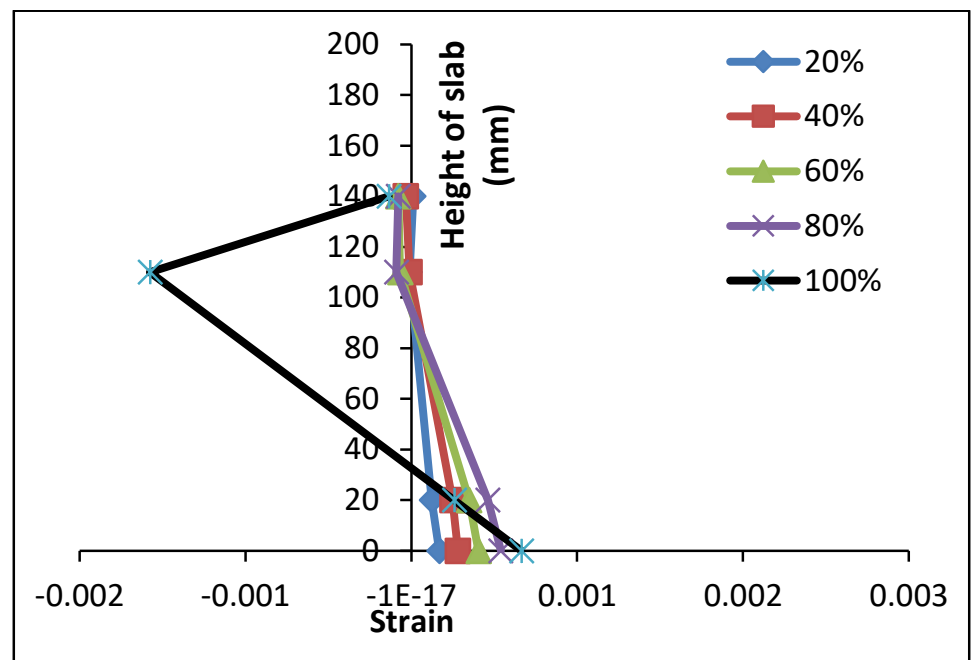

b)

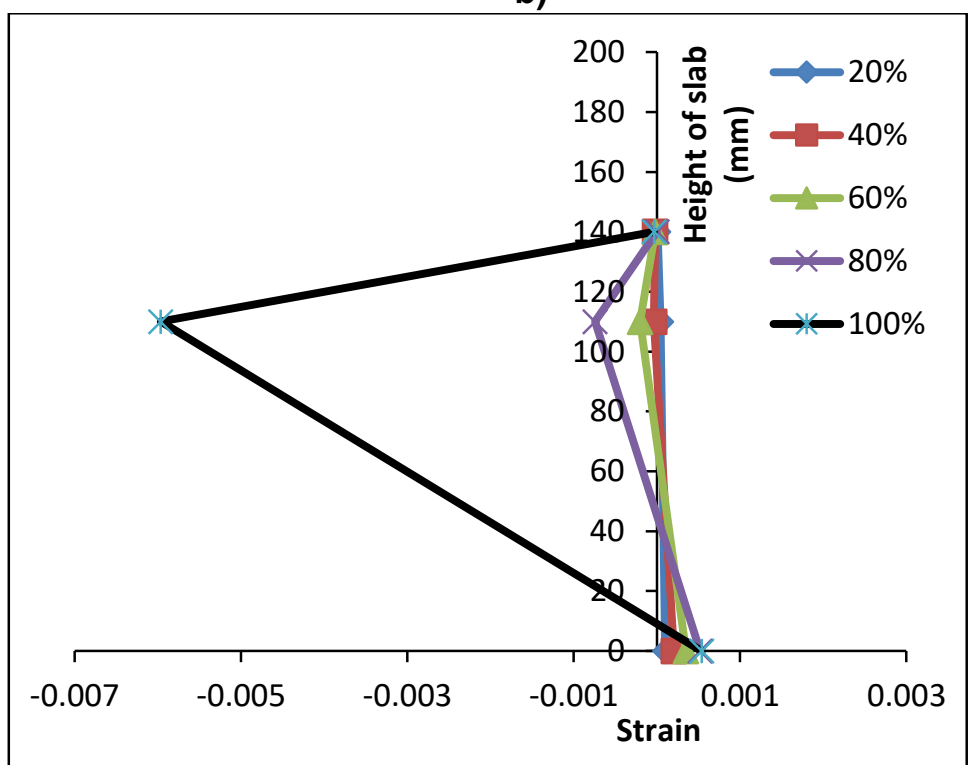

d)

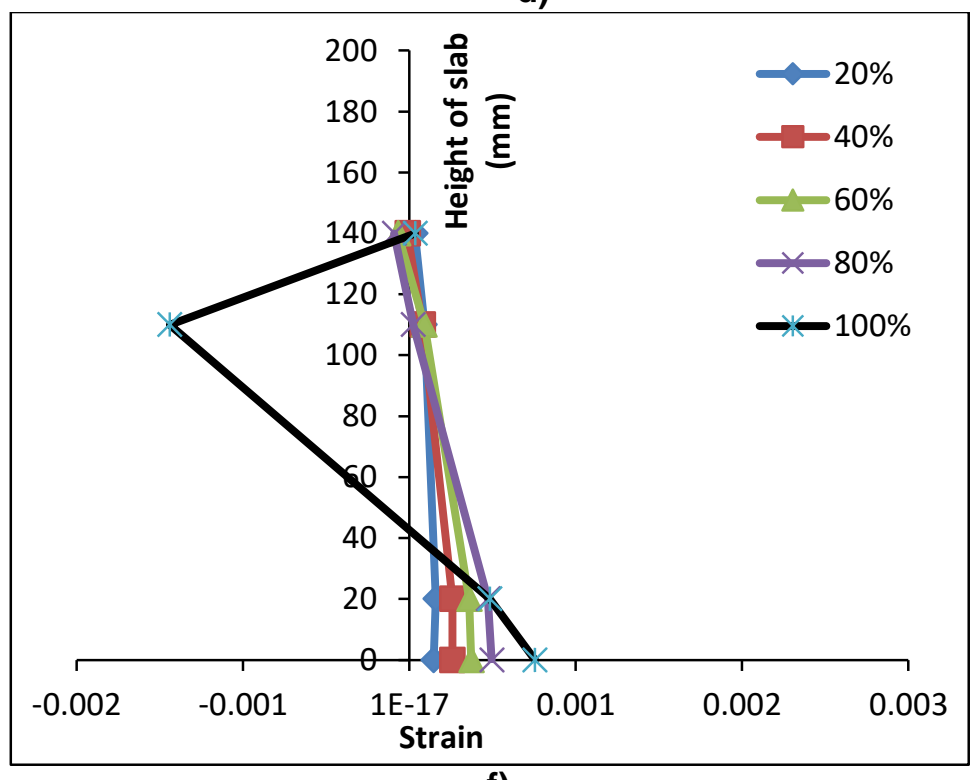

f)

Fig 12. Strain distribution across the panel's thickness at mid-span of: a) SS1; b) SS2; c) ST1;

d) ST2; e) SL1; f) SL2 

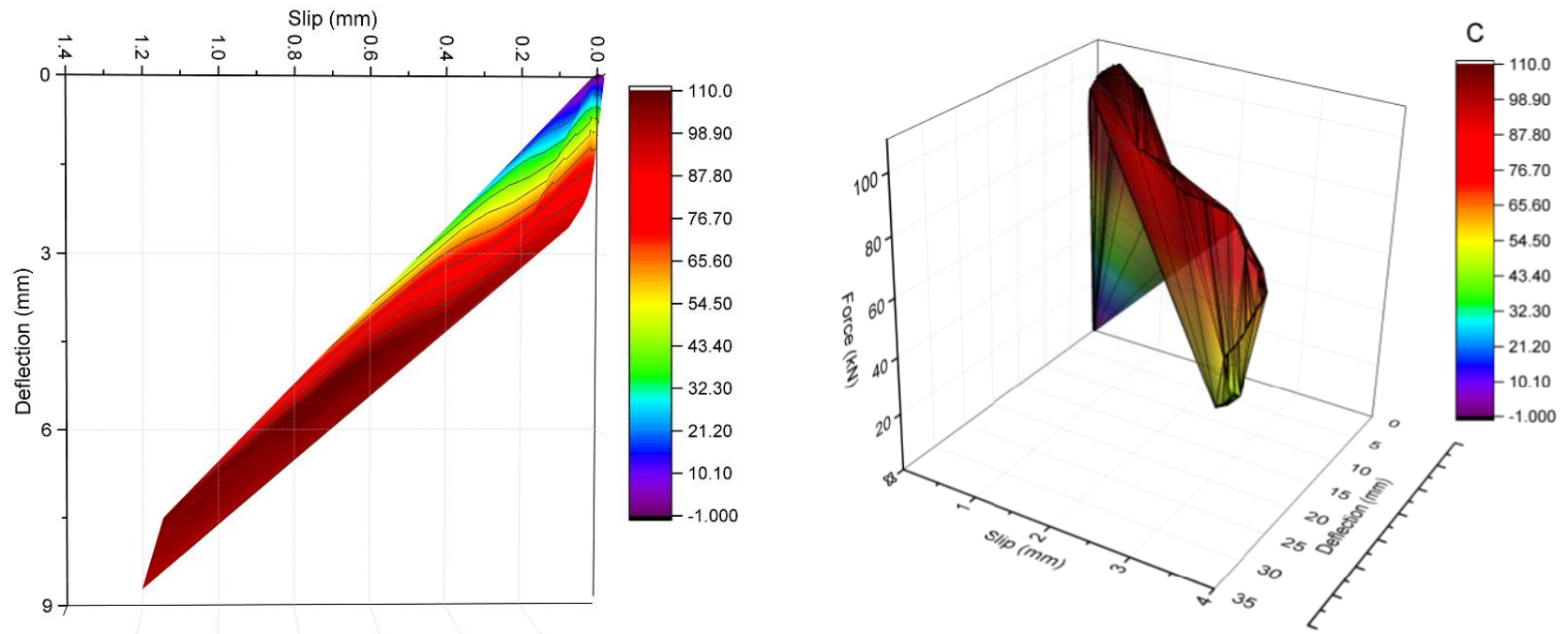

a)
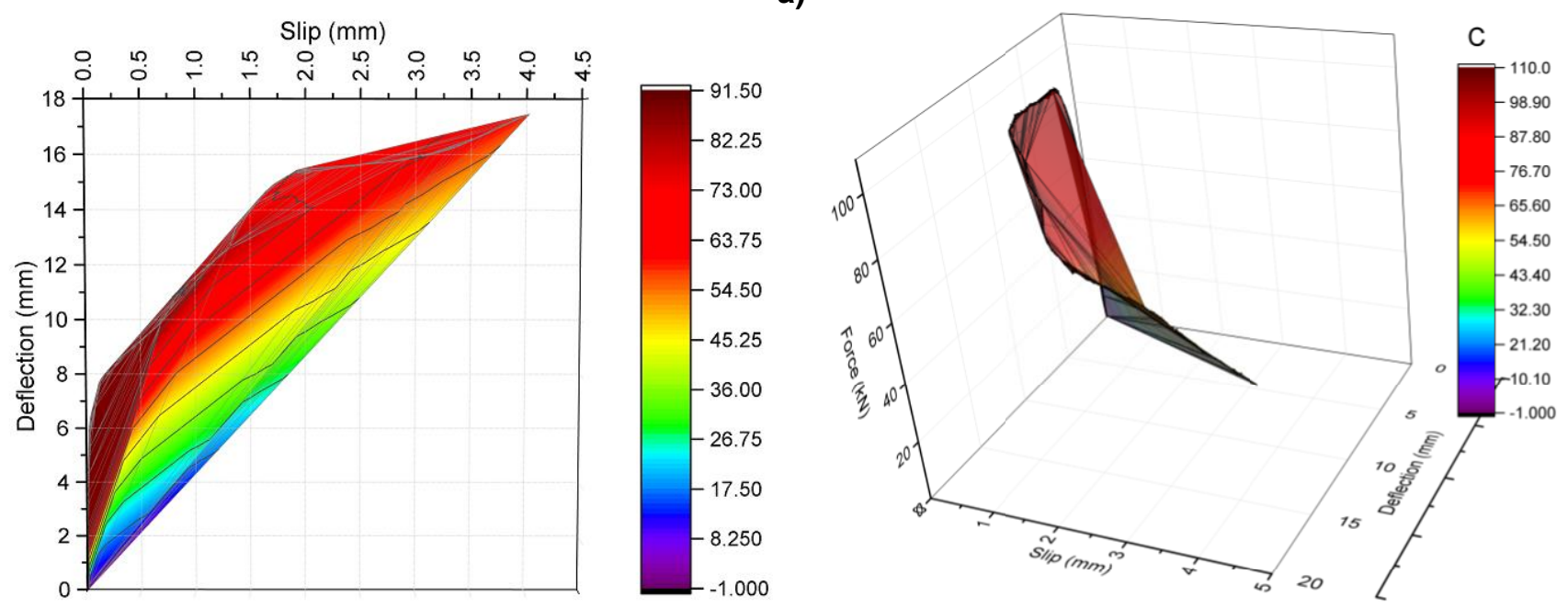

b)
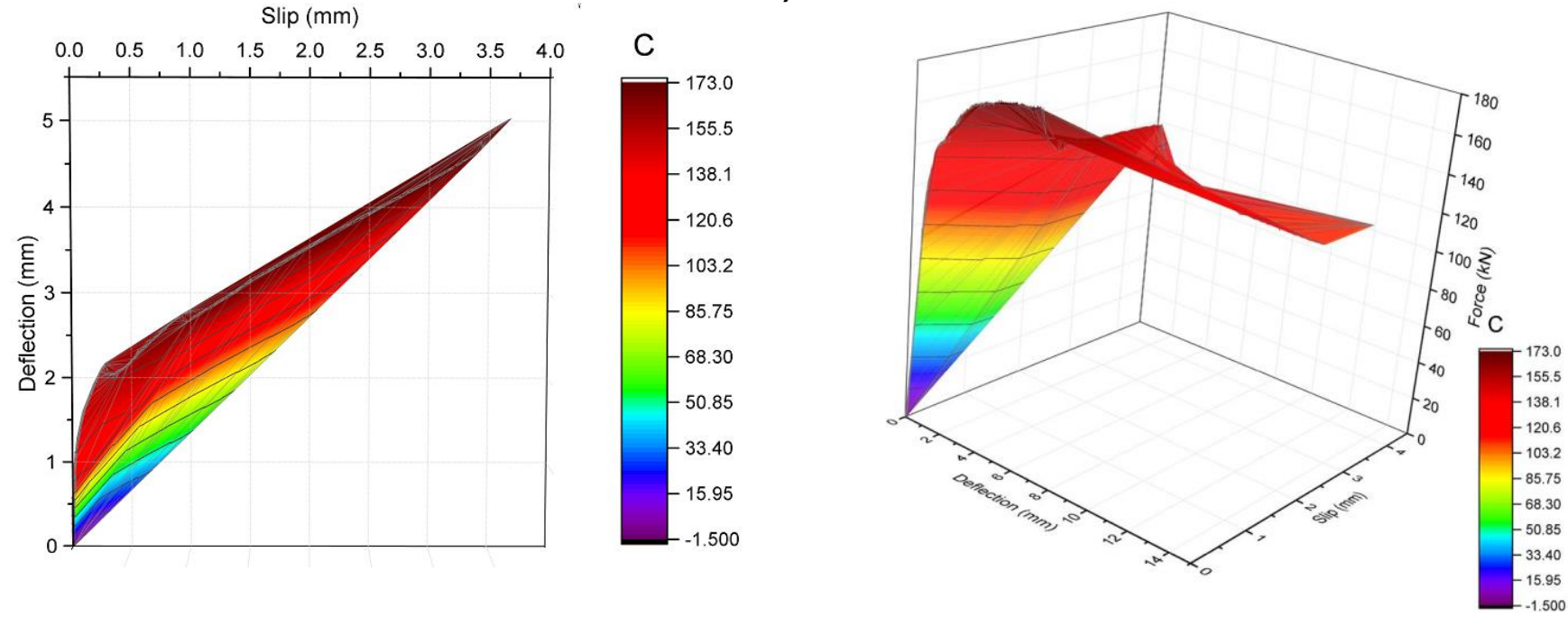

c) 

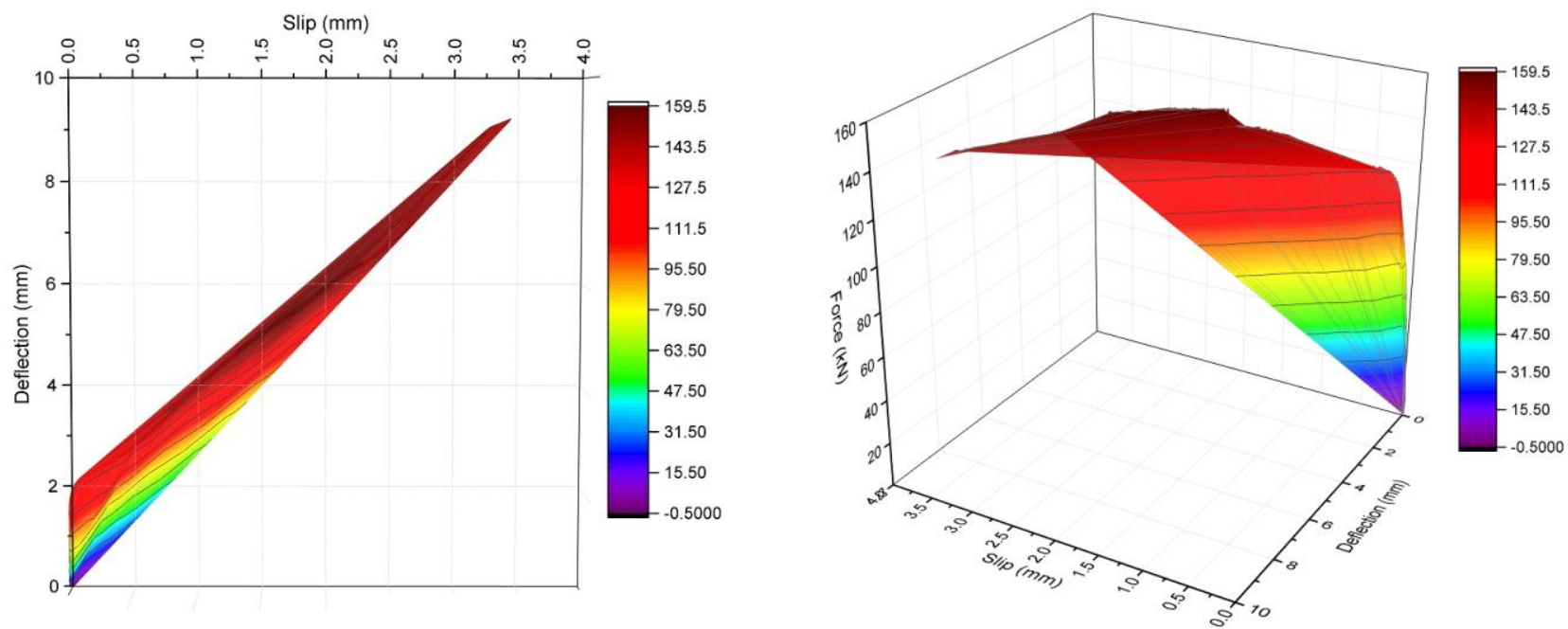

d)
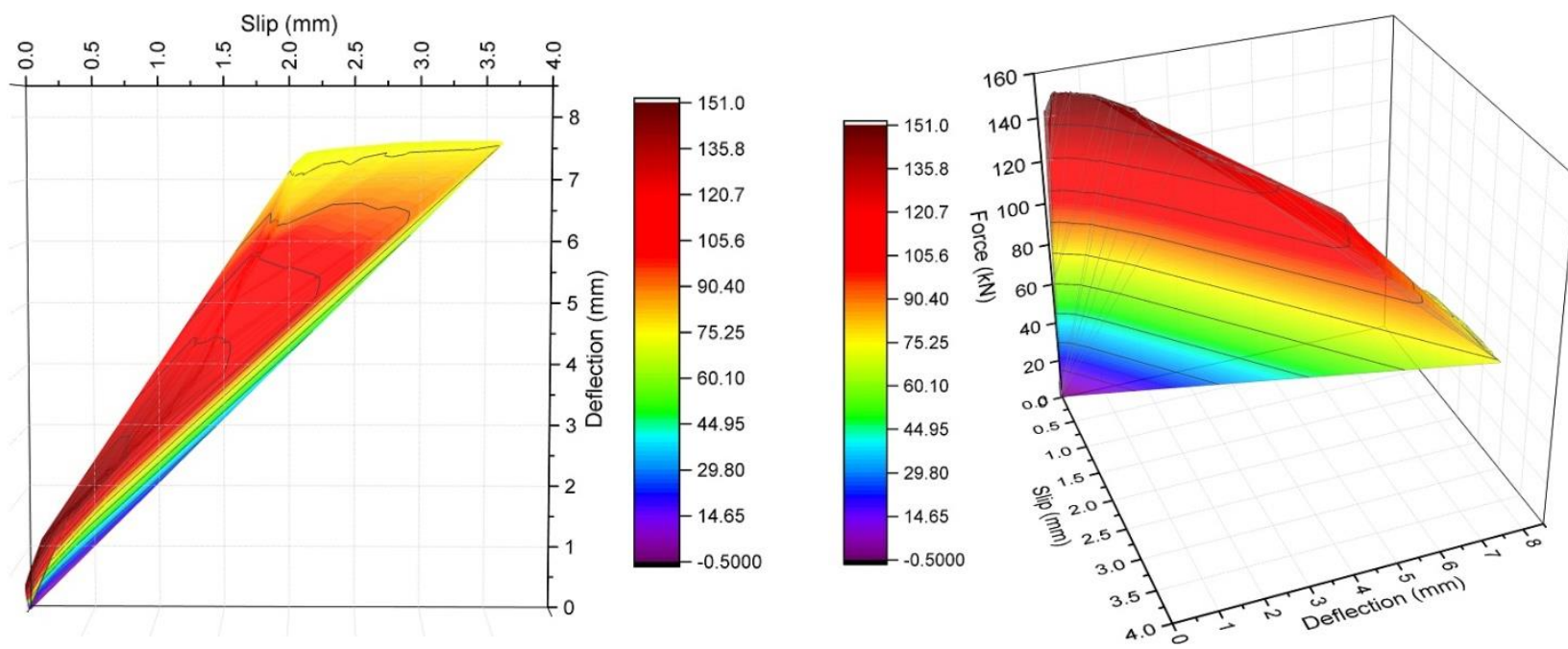

e)
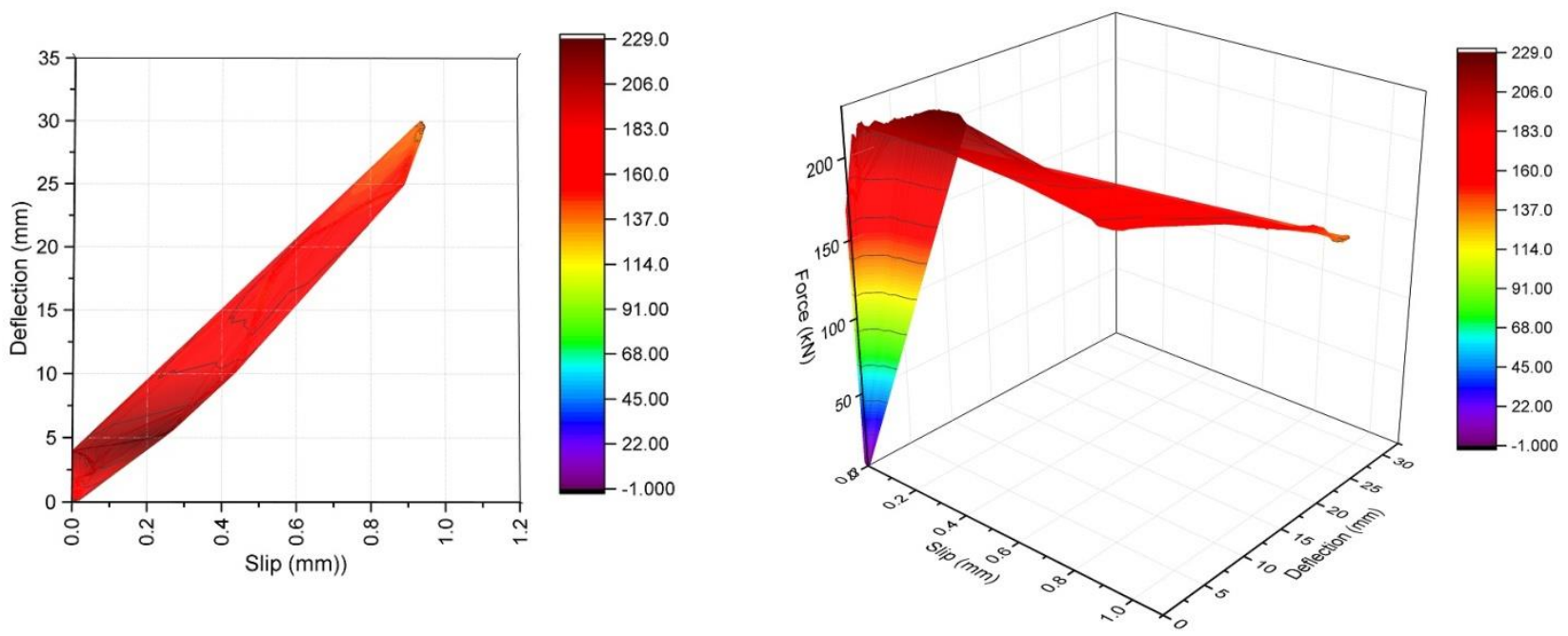

f)

Fig 13. Three-dimensional plots of the force along variations of deflection and slip for specimens of: a) SS2; b) ST2; c) SL2; d) SS1; e) ST1; f) SL1 


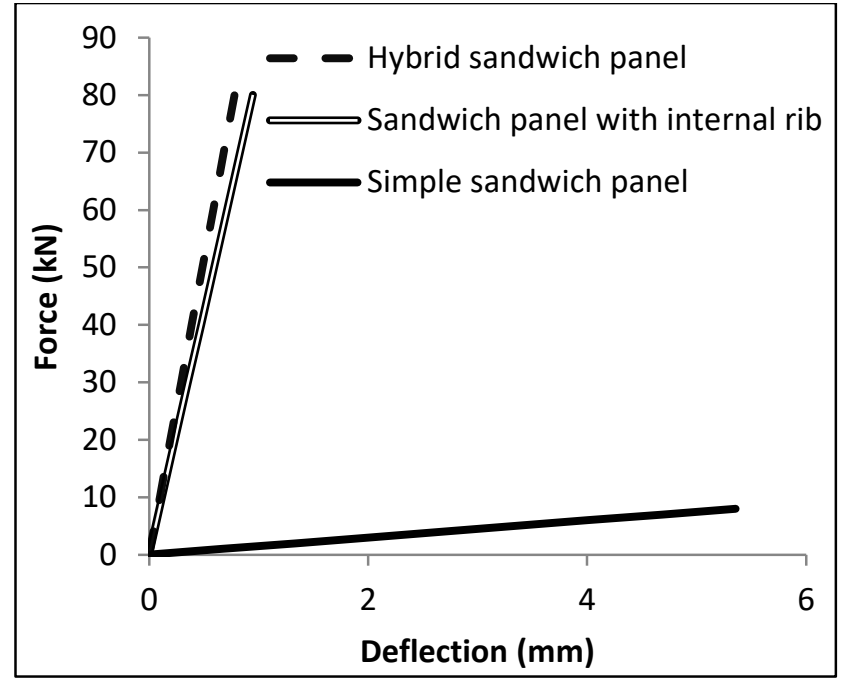

a)

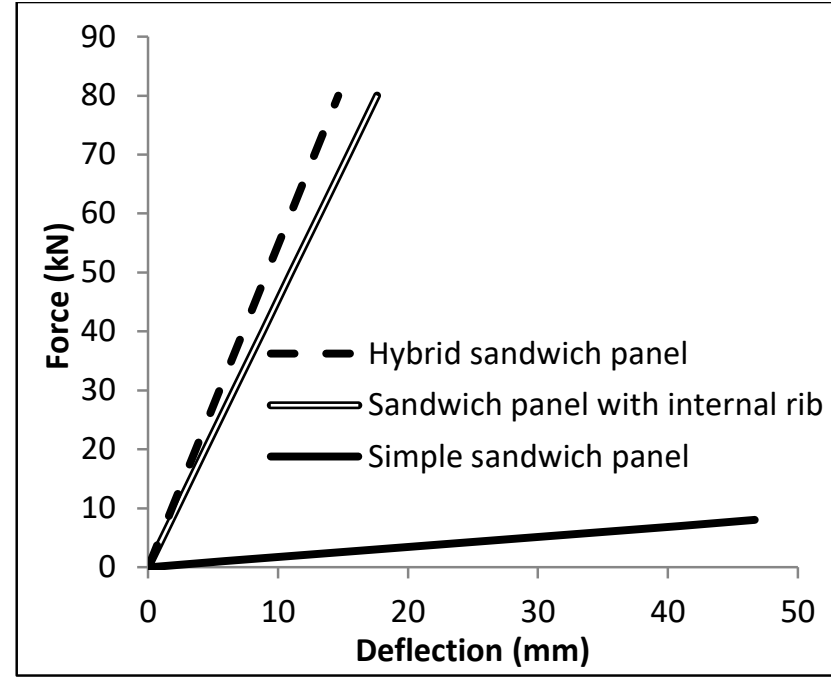

b)

Fig 14. The obtained force-deflection responses for slabs submitted under load condition with a span ratio of 2: a) Slab 1; b) Slab 2 
Table 1. Geometrical properties of the proposed slabs in details

\begin{tabular}{|c|c|c|c|c|}
\hline \multirow{2}{*}{ Name } & \multicolumn{2}{|c|}{ Height $(\mathbf{m m})$} & \multicolumn{2}{c|}{ Width (mm) } \\
\cline { 2 - 5 } & Slab 1 & Slab 2 & Slab 1 & Slab 2 \\
\hline A & 149 & 115 & --- & --- \\
\hline B & 20 & 20 & --- & --- \\
\hline C & 3 & 5 & --- & --- \\
\hline D & 119 & 85 & --- & --- \\
\hline E & 160 & 130 & --- & 260 \\
\hline F & 50 & 50 & --- & 400 \\
\hline G & --- & --- & 260 & 4 \\
\hline H & --- & --- & 400 & 200 \\
\hline I & --- & --- & 6 & 130 \\
\hline K & --- & --- & 200 & 40 \\
\hline L & --- & --- & 130 & 40 \\
\hline M & --- & -- & & \\
\hline
\end{tabular}

Table 2. The obtained mechanical properties for ribs and skins

\begin{tabular}{|c|c|c|c|c|}
\hline & Coupon specimens & $\begin{array}{c}\text { Tensile strength } \\
\text { (MPa) }\end{array}$ & $\begin{array}{l}\text { Elastic modulus } \\
(\mathrm{GPa})\end{array}$ & $\begin{array}{c}\text { Ultimate } \\
\text { strain (\%) }\end{array}$ \\
\hline \multirow{5}{*}{ Slab 1} & Rib- Oriented fibers at 00 & 170.80 & 13.18 & 2.59 \\
\hline & Rib- Oriented fibers at 900 & 98.35 & 15.96 & 1.41 \\
\hline & Rib- Oriented fibers at 45음 & 332.21 & 15.07 & 2.20 \\
\hline & Skin- Oriented fibers at 900 & 27.03 & 13.30 & 0.20 \\
\hline & Skin- Oriented fibers at 0 o & 785.68 & 31.41 & 2.50 \\
\hline \multirow{5}{*}{ Slab 2} & Rib- Oriented fibers at $0 \cong$ & 112.50 & 13.03 & 2.40 \\
\hline & Rib- Oriented fibers at 900 & 61.08 & 8.62 & 1.51 \\
\hline & Rib- Oriented fibers at 450 & 174.01 & 11.64 & 2.35 \\
\hline & Skin- Oriented fibers at 900 & 27.90 & 12.10 & 0.26 \\
\hline & Skin- Oriented fibers at 0음 & 573.02 & 36.03 & 1.66 \\
\hline
\end{tabular}


Table 3. Used different types of sandwich panels in the numerical simulations

\begin{tabular}{|c|c|c|c|}
\hline Slab name & Schematic figures of slabs & \multicolumn{2}{|c|}{ Component placements } \\
\hline \multirow{3}{*}{ Simple sandwich panel } & & Top & GFRP skin \\
\hline & & Middle & Foam core \\
\hline & & Bottom & GFRP skin \\
\hline \multirow{3}{*}{$\begin{array}{l}\text { Sandwich panel with } \\
\text { internal rib }\end{array}$} & & Top & GFRP skin \\
\hline & & Middle & GFRP rib + foam core \\
\hline & & Bottom & GFRP skin \\
\hline \multirow{3}{*}{ Hybrid sandwich panel } & & Top & Reinforced mortar \\
\hline & & Middle & GFRP rib + Foam core \\
\hline & & Bottom & GFRP skin \\
\hline
\end{tabular}

Table 4. Calculated flexural and shear stiffness for composite slabs

\begin{tabular}{|c|c|c|c|c|c|c|}
\cline { 2 - 7 } \multicolumn{1}{c|}{} & \multicolumn{2}{c|}{ Hybrid sandwich panel } & \multicolumn{2}{c|}{$\begin{array}{c}\text { Sandwich panel with } \\
\text { internal rib }\end{array}$} & \multicolumn{2}{c|}{ Simple sandwich panel } \\
\cline { 2 - 7 } & Slab 1 & Slab 2 & Slab 1 & Slab 2 & Slab 1 & Slab 2 \\
\hline El [N.mm $\left.{ }^{2}\right]$ & 276.0 E 10 & 166.0 E 10 & 132.0 E 10 & 130.0 E 10 & 6.4 E 10 & 6.0 E 10 \\
GA [N] & 153.6 E 5 & 928.0 E 4 & 153.6 E 5 & 928.0 E 4 & 204.8 E 3 & 185.6 E 3 \\
\hline
\end{tabular}

